\title{
Los adjetivos relacionales desde una perspectiva diacrónica: características morfológicas, sintácticas y semánticas ${ }^{1}$
}

Se explicita a lo largo del trabajo un proceso de cambio lingüístico y se observa cómo el adjetivo relacional parece estar en una posición periférica dentro de la categoría del adjetivo. Se parte de la hipótesis de que el adjetivo relacional se comporta en español antiguo en cierta medida como un nombre, sustituyendo a un genitivo, y se observa que el proceso de cambio ha ido desde una situación en la que el adjetivo posee un único valor de relación, similar al genitivo - muchas restricciones semánticas - y no presenta casi restricciones sintácticas, hasta la situación contraria: máximas restricciones sintácticas y mínimas restricciones semánticas.

\section{Introducción: precedentes y objetivos de la investigación}

El objetivo primordial de este estudio es mostrar la situación de los adjetivos relacionales en español medieval y ofrecer una explicación de la evolución morfológica, sintáctica y semántica que han sufrido desde la época de orígenes, para, así, llegar a proponer una hipótesis sobre los diversos factores que provocan los cambios. El análisis de su evolución diacrónica nos orientará hacia una interpretación de cómo y por qué han ido teniendo lugar ciertos cambios, y nos permitirá entender cómo se ha llegado a la situación actual que presenta, en algunos casos, notables diferencias con épocas anteriores del idioma.

En primer lugar, antes de llevar a cabo este análisis, se hace necesario aclarar las características del tipo de adjetivos que voy a analizar. Así, entre los rasgos que definen a estos adjetivos, que no presentan estados acotados temporalmente, podemos mencionar los siguientes: su formación a partir de nombres (diente - dental); la obligación de posponerse al nombre al que

\footnotetext{
${ }^{1}$ Este trabajo de investigación se inscribe en el marco de un proyecto investigador de carácter más amplio que llevamos a cabo un grupo de profesores de la Universidad Autónoma de Madrid: «Vieja y nueva sintaxis: la emergencia de la norma sintáctica del castellano», financiado por el Ministerio de Educación y Ciencia. Este grupo dirigido por Javier Elvira y formado también por Inés Fernández Ordóñez, Javier García, Santiago U. Sánchez y Jacinto González está analizando, desde diferentes perspectivas, la naturaleza del cambio lingüístico, así como el conjunto de fenómenos sujetos a variación gramatical en el español. Asimismo, esta investigación ha sido financiada con la ayuda de otros dos proyectos: el primero: «Principios universales y variación en el proceso de extensión metafórica. Un nuevo concepto de diccionario de expresiones idiomáticas con verbos de movimiento» (UAM y Comunidad Autónoma de Madrid) está dirigido por Elena de Miguel, y el segundo HUM2005-08119/FILO: «¿Existe un reajuste sintáctico en español clásico?: funciones sintácticas y cambios sintácticos y morfológicos en el periodo 1450 -1726» está dirigido por José $\mathrm{M}^{\mathrm{a}}$ García Martín.
} 
modifican (*mecánico taller): la imposibilidad, que luego será cuestionada, de ser usados predicativamente (*la crítica es musical); el no poder entrar en comparaciones o ser modificados por adverbios de grado (*clínica muy dental); la imposibilidad de presentar antónimos (*amecánico); la imposibilidad de coordinación con adjetivos valorativos (*taller mecánico y viejo); la relación de adyacencia con el nombre modificado, la posibilidad de recibir prefijación culta, su cercanía a los nombres, etc. Todos estos criterios aparecen recogidos en Demonte (1999, 137s.), donde se definen estos adjetivos como aquellos que, frente a los calificativos, que se refieren a un rasgo constitutivo del nombre modificado, no se refieren a una sola propiedad del nombre sino que expresan un conjunto de propiedades y las vinculan a las del nombre al que acompañan, dando lugar, así, a relaciones semánticas más complejas y diversificadas.

En español actual parece, pues, a la vista de lo dicho, que estos adjetivos responden - de forma relativamente estable - a una serie de pruebas, que nos permiten diferenciar entre adjetivos calificativos y relacionales. No ocurre lo mismo en español antiguo ya que algunos de estos criterios, que estudiaré en profundidad a lo largo de esta investigación, no funcionan igual que en la actualidad; así, existe la posibilidad de anteposición y de gradación, la ausencia de prefijación culta, la coordinación con adjetivos valorativos ... Por tanto, estos parámetros, considerados válidos para el español actual, serán cuestionados en el sentido de que no siempre se trata de criterios que nos permitan identificar estos adjetivos en la época medieval. Hemos de tener en cuenta que estamos ante una categoría en formación que en español antiguo no está aún bien definida, lo que provoca importantes vacilaciones, que iré analizando en este estudio. ${ }^{2}$

Los hechos lingüísticos nos permitirán observar que estamos ante un tipo de adjetivo en constante evolución desde la antigüedad y que sus características actuales solo pueden ser entendidas en su globalidad si conocemos los pasos que han ido siguiendo desde su creación, en ocasiones en el propio latín, y su expansión en español antiguo. En este trabajo voy a presentar dicha evolución, de forma que se puedan aportar ciertas explicaciones sobre el comportamiento sintáctico de estos adjetivos, diferente en muchos aspectos al de los demás adjetivos españoles, y sobre cuándo y cómo - y, si es posible, por qué - tiene lugar el cambio semántico que traslada a algunos de ellos hacia otra categoría de adjetivos.

Quiero destacar, en este sentido, la novedad que supone este trabajo ya que se presenta un análisis diacrónico de un grupo de adjetivos que, hasta el momento, solo han sido analizados en sincronía. A lo largo del trabajo analizaré la documentación medieval y esta nos servirá para entender que estamos

\footnotetext{
${ }^{2}$ Sí era una categoría fijada en latín pero su uso era menor que en español, dado que, como a continuación señalaré, la relación expresada por estos adjetivos correspondía habitualmente al genitivo nominal.
} 
ante un lento proceso de nuestra lengua, ya que la creación de este tipo de adjetivos es gradual en el tiempo; así como su fijación, que en la época antigua no es tal todavía. Al tiempo, creo que podré demostrar, teniendo en cuenta los criterios propuestos, que el límite entre valorativo y relacional, a nivel sintáctico, no semántico, no está tan claro en español medieval en el sentido de que las características que teóricamente cumplen los adjetivos relacionales hoy en día no aparecen aún definidas. Pero este trabajo se plantea como un estudio innovador no solo por el objeto de estudio sino también por las herramientas utilizadas para llevar a cabo el análisis, por la metodología, pues propongo la aplicación de una serie de criterios que hasta ahora solo se han utilizado en sincronía a la evolución diacrónica de los adjetivos.

Antes de mostrar las conclusiones que puedan extraerse del análisis del corpus utilizado, se hace imprescindible presentar, aunque sea de forma muy breve, el estado de las investigaciones en torno al tema que voy a tratar. En todas las gramáticas del español se ha prestado, obviamente, atención a los adjetivos y son muchas las clasificaciones que de ellos se han postulado, aunque no es mi intención en este momento entrar a discutir estas. ${ }^{3}$ Es evidente que la categoría «adjetivo» engloba unidades de carácter muy diverso; ${ }^{4}$ ya Alcina y Blecua $(1975,507)$ hacían referencia a esta realidad:

«El apartado que tradicionalmente se dedica a los adjetivos comprende nombres que por su significado expresan cualidad inherente al sujeto (tamaño, forma, color, capacidad, extensión, materia, o bien cualidad moral, valoración de conducta, etc.), o bien la relación del sujeto con respecto al origen; situación social, cultural, religiosa, política, técnica, ciencia; pertenencia o filiación, o por último el estado producido por una acción».

De entre esta diversidad, he seleccionado para mi estudio un tipo de adjetivos: los relacionales, que no siempre han sido identificados como un subgrupo específico dentro de los adjetivos, pero que tienen un interés especial por su diferente comportamiento a lo largo de nuestra historia lingüística.

\footnotetext{
${ }^{3}$ Distintas propuestas pueden consultarse en RAE (1973) donde se establece la diferencia entre adjetivos calificativos y pronombres adjetivos; en Alcina/Blecua (1975), quienes siguen la clasificación tradicional: adjetivos especificativos y adjetivos explicativos; en Fernández Ramírez (1986), que considera que existe una escala de valores del adjetivo, «que iría gradualmente desde los que poseen elementos expresivos o funcionan ocasionalmente con intención expresiva hasta los que analizan y describen, o hasta los que determinan fijando el concepto de la mención» (ib., 86s.); en Alarcos (1994) que distingue los adjetivos calificativos de los determinativos, que tienen mayores restricciones posicionales; en el trabajo ya mencionado de Violeta Demonte (1999), etc.

${ }^{4}$ Entre las muchas definiciones de «adjetivo» recojo una de carácter funcional propuesta por José Antonio Martínez (1994, 222): «(sub)categoría de sintagmas nominales que, al margen de la transposición, entra en subordinación con los de categoría sustantiva y a la cual se subordinan los de categoría adverbial».
} 
Además de las gramáticas mencionadas, son también muchos los estudios sincrónicos dedicados al análisis de distintos aspectos de los adjetivos: su colocación, su capacidad para convertirse en predicados, sus posibilidades de aceptar gradación, etc. Algunos de estos se mencionan en la bibliografía final. Por otra parte, desde hace muchos años, distintos investigadores se han enfrentado al estudio de la posición del adjetivo en español antiguo. En este sentido, el clásico trabajo de Lapesa (1975) sobre la posición del adjetivo atributivo en español sigue siendo un punto de partida imprescindible. Asimismo, el trabajo de Javier García González (1990) es muy iluminador para conocer en profundidad los diferentes factores que influyen en la evolución que experimenta la posición de los adjetivos a lo largo de la Edad Media.

Más recientes son los trabajos de Bosque (1993), Demonte (1999), Rainer (1999), Almela (2000), Santos Río (2000) o Fábregas (2005), preocupados por las distintas características de los adjetivos relacionales. Estos trabajos son de eminente corte sincrónico, al igual que el estudio de R. Abad (2004), quien es la primera en aplicar a este tipo de adjetivos la teoría de Pustejovsky (1995). Tanto estos estudios como los anteriormente mencionados me servirán de punto de partida para asentar las bases de este trabajo.

\section{Presentación y análisis de los datos}

Presento, a continuación, un corpus compuesto por 50 adjetivos relacionales usados en español medieval. En latín clásico estos adjetivos eran menos frecuentes que en romance; de hecho de los 50 adjetivos que voy a analizar 19 son de creación romance (un 38\%), lo que implica que estamos ante un proceso en expansión, ya que a los adjetivos latinos conservados se sumarán nuevos adjetivos creados por el mismo procedimiento. ${ }^{5}$ Hay un punto importante sobre el que quiero llamar la atención, en este sentido: la desaparición del sufijo de flexión del genitivo ha sido compensada por morfemas derivativos, ya no flexivos, con los que se crea este tipo de adjetivos. El incremento de este tipo de adjetivos está, pues, motivado, en gran medida, por la caída de los casos.

Por otra parte, he de señalar que el número de estos adjetivos, así como su frecuencia de uso, es sensiblemente inferior al existente en el español moderno. Son adjetivos formados por derivación a partir de nombres y un proceso como este parece ser un proceso gradual, que, prácticamente, está solo esbozado en los primeros tiempos de nuestra lengua. Como señala Javier García González (1990), en El Cid se recurre a los adjetivos en 548 ocasiones y, para ilustrar la escasez de adjetivos relacionales, tenemos que recordar que,

\footnotetext{
${ }^{5}$ Estos adjetivos de creación romance, o posiblemente del latín vulgar, son los siguientes: angelical, campal, candeal, carnicero, cavallar, estrellero, francés, greciano, monedado, montesa, morisco, mundanal, obispal, palaçiano, serrano, umanal.
} 
según el cómputo realizado por este autor, estos suman un 7,5\% de los adjetivos aparecidos. Esta proporción va elevándose a medida que transcurre la época medieval pero todavía en los textos analizados por García González en el siglo XV solo hay un $10,75 \%$.

Antes de comentar las características semánticas y morfosintácticas, me detendré en la presentación y en la justificación de la nómina de adjetivos que se analizarán en este estudio.

2.1. Nómina de adjetivos analizados y justificación de la selección

\begin{tabular}{|l|l|l|l|l|}
\hline 1. ageno & 11. cavallar & 21. estrellero & 31. montesa & 41. real \\
\hline 2. angelical & 12. celestial & 22. francés & 32. morisco & 42. romano \\
\hline 3. angélico & 13. comunal & 23. greciano & 33. mortal & 43. rústico \\
\hline 4. añal & 14. criminal & 24. griego & 34. mundanal & 44. seglar \\
\hline 5. ballestero & 15. cristiano & 25. humano & 35. mundano & 45. serrano \\
\hline 6. campal & 16. dental & 26. marino & 36. municipal & 46. spirital \\
\hline $\begin{array}{l}\text { 7. candeal } \\
\text { - candial }\end{array}$ & 17. divinal & 27. marital & 37. natural & 47. terrenal \\
\hline 8. carnal & 18. divino & 28. matrimonial & 38. obispal & 48. toledano \\
\hline 9. carnicero & 19. elegíaco & 29. molar & 39. palaçiano & 49. umanal \\
\hline 10. castellano & 20. extraña & 30. monedado & 40. público & 50. ynfernal \\
\hline
\end{tabular}

Me gustaría señalar el criterio seguido para la elección de los adjetivos analizados, así como referirme a los textos que he tenido en cuenta en este análisis. En primer lugar, para realizar la selección he atendido a los criterios propuestos por Demonte (1999) y Rainer (1999), que diferencian entre adjetivos relacionales y calificativos. ${ }^{6}$ Una vez establecida una mínima base teórica, he comenzado mi recogida de datos a partir de la nómina de los adjetivos relacionales que aparecen en El Cid, Los Milagros de nuestra Señora, El Libro de Buen Amor y en algunos fragmentos de la Primera Crónica General de Alfonso X, El Corbacho, La Celestina y el Laberinto de Fortuna y he decidido incluir en mi estudio los adjetivos que aparecen con cierta frecuen-

${ }^{6}$ A la vista de alguno de estos adjetivos, se podría pensar, según nuestro criterio actual, que estamos ante calificativos; a lo largo del trabajo, sin embargo, se presentarán casos en los que se observa claramente su uso como relacional. Asimismo, observamos pares formados sobre la misma base como angélico-angelical, humano-humanal, divino-divinal o mundano-mundanal que no han especializado su uso. En este sentido, véanse las reflexiones de Bosque (1990, 119s.) sobre la especialización en el uso relacional de adjetivos como caballar frente a otros como caballuno, que se generalizan con valor calificativo. 
cia, dejando al margen los que solo se usan de forma esporádica (elimino, pues, de mi lista algunos como gallizano, argólica, espérica ... cuya presencia en estos textos es mínima). He tomado también la decisión de incorporar en mi corpus adjetivos con diverso grado de transparencia para ver si esta ausencia de transparencia tiene alguna repercusión en su comportamiento sintáctico; así incluyo adjetivos como extraño, público, ageno, rústico o divino cuya relación con el nombre del que derivan no es transparente para el hablante.

Obviamente, la nómina de adjetivos seleccionados se podría alargar con más adjetivos que, al igual que los analizados, indiquen procedencia, pertenencia, finalidad, origen, nacionalidad, materia, tipo, grupo, etc., cuya presencia, aunque sea mínima, también está atestiguada en estas obras; no obstante, he optado por no alargar excesivamente el corpus de datos manejados pues creo que la muestra presentada resulta variada y es lo suficientemente representativa de la situación en español medieval ya que recoge muchos de los adjetivos relacionales que aparecen desde los inicios de nuestra lengua.

Tras establecer esta primera selección de adjetivos, he realizado unas calas sistemáticas en el CORDE para mostrar su comportamiento, estableciendo como límite temporal el año 1500. Aunque sé que es arbitraria, esta limitación temporal responde al criterio generalizado de lo que se considera época medieval; no obstante, también he utilizado algunos ejemplos que sobrepasan estos límites, dado que parece obvio que un cambio de década o de siglo no implica un cambio en la forma de expresarse de los hablantes y porque, por otra parte, los datos del español clásico pueden resultarnos muy útiles para entender la evolución en el uso de estos adjetivos.

Una vez aclarado el punto desde el que parte esta investigación, pasaré al análisis morfológico, sintáctico y semántico de estos adjetivos.

\subsection{Morfología de los adjetivos relacionales}

Es bien sabido que en latín la expresión de la relación o pertenencia se indicaba, habitualmente, con un sustantivo en genitivo que modificaba a otro sustantivo (lar familiae, amor Dei). Una vez que comienza la caída de los casos, esta relación se expresa mediante un sustantivo precedido por la preposición $d e$; pero también existe, desde antiguo, la posibilidad de expresar tal relación mediante adjetivos que provienen de nombres y que se crean mediante la adición de sufijos derivativos. Ernout y Thomas $\left({ }^{2} 1953,44 \mathrm{~s}\right.$.) hacen referencia a la relación entre adjetivos relacionales (aunque ellos no les dan esta denominación) y el genitivo latino. Según estos autores, a veces un adjetivo derivado de un nombre podía expresar una relación equivalente a la que expresa un genitivo; estos usos adjetivales son muy antiguos y en latín clásico es posible encontrar ejemplos que designaban nombres de divinidades o personajes importantes: sacerdos Ueneria (Pl. Ru. 329) en vez de sacerdos Ueneris o a nombres que indican el estado social o familiar: lar familiaris 'patri- 
monio familiar', en vez de lar familiae. La idea que subyace a esta situación es que algunos valores de los adjetivos de relación son equivalentes a los que asumía el genitivo en latín. Por ejemplo, el llamado genitivo de referencia se combinaba, entre otros, con apelativos geográficos: urbs Romae, que tiene valor parecido a ciudad castellana; otros casos del genitivo subjetivo (amor Dei) aparecen expresados a través de adjetivos relacionales (amor divino; Bassols 1971, vol. 1, 88).

En este sentido, como ya avanzaba, este proceso se ha potenciado en romance ya que la desaparición del sufijo de flexión se ha visto compensada por la incorporación de morfemas derivativos que, añadidos a los nombres, sirven para crear adjetivos que, funcionalmente, son idénticos a los antiguos sustantivos genitivos. Este es un punto de partida fundamental puesto que va a tener, como después veremos, importantes repercusiones sintácticas.

Nos encontramos, pues, ante adjetivos que provienen de nombres a través de una serie de sufijaciones que pueden ser variadas. He aquí una muestra de los sufijos más usados desde el principio (Rainer 1999 y Abad 2004). Se trata de procedimientos latinos de creación de palabras que siguen siendo productivos en castellano. ${ }^{7}$

-AL: ángel - angelical; año - añal, campo - campal, cande -
candeal, carne - carnal, cavallo - cavallar, ${ }^{8}$ crimen - crimi-
nal, común - comunal, diente - dental, marido - marital,
matrimonio - matrimonial, muela - molar, muerte - mor-
tal, municipio - municipal, natura - natural, obispo - obis-
pal, rey - real, siglo - seglar, espíritu - spirital, terreno -
terrenal, infierno - infernal.

En ocasiones el sufijo -AL se suma a una base adjetiva, que a su vez deriva de un nombre: cielo - celeste - celestial, DIvUs - divino - divinal, номо humano - humanal, mundo - mundano - mundanal.

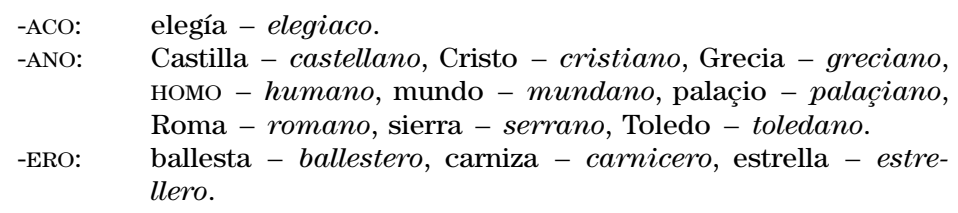

\footnotetext{
${ }^{7}$ Como ya avancé, muchos de estos adjetivos se crean en el propio latín. Así: ageno < ALIENUS, angélico < ANGELICUS, añal < ANNALIS, ballestero < BALLISTARIUS, carnal < CARNALIS, castellano < CASTELLANUS, comunal < COMMUNALIS, criminal < CRIMINALIS, cristiano < CRISTIANUS, dental < DENTALIS, divinal < DIVINALIS, divino < DIVINUS, elegiaco < ELEGIACUS, estranna < EXTRANEUS, griego < GRAECUS, humano < HUMANUS, marino < MARINUS, marital < MARITALIS, matrimonial < MATRIMONIALIS, molar < MOLARIS, mortal < MORTALIS, mundano < MUNDANUS, municipal < MUNICIPALIS, natural < NATURALIS, público < PUBLICUS, real < REGALIS, romano < ROMANUS, rústico < RUSTICUS, seglar < SAECULARIS, spirital < SPIRITUALIS, toledano < TOLETANUS, ynfernal < INFERNALIS.

8 -AR es alomorfo de -AL.
} 


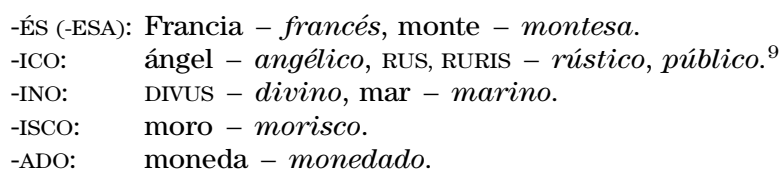

En algunos casos su origen no es transparente pues responden a adjetivos creados en latín sobre bases que han evolucionado: es el caso de ageno < ALIENUS < ALIUS, divino < DIVUS o estranno < EXTRANEUS. Hay también un ejemplo, griego, que no se forma por sufijación sino por regresión ya en latín: GRAECUS < GRAECIA.

Tabla 1: Procedimientos de formación de adjetivos

\begin{tabular}{|l|l|}
\hline -AL & 25 \\
\hline -ANO & 9 \\
\hline -ICO & 3 \\
\hline -ERO & 3 \\
\hline -ÉS & 2 \\
\hline -INO & 2 \\
\hline -ACO & 1 \\
\hline -ISCO & 1 \\
\hline -ADO & 1 \\
\hline otros procedimientos & 3 \\
\hline
\end{tabular}

A la vista de los datos, comprobamos que estamos ante los mismos sufijos que se emplean en español actual para crear adjetivos relacionales (constitucional, picassiano, camisero, pesquera ...). Morfológicamente, pues, hay a lo largo de la historia de nuestra lengua una continuidad en la creación de estos adjetivos; no obstante, quiero destacar que el sufijo -AL - que, al igual que ahora, es el predominante: 25 casos de los 50 adjetivos analizados, lo que supone un $50 \%$, cifra nada desdeñable -, va siendo cada vez más productivo porque, si bien procede de la forma latina -ALIS, -ALE, este esquema se ha potenciado en español y, si en los primeros tiempos del idioma su predominio era relativo, poco a poco se observa un aumento en su uso, tendencia que se va a mantener hasta hoy en día, cuando se ha convertido en el principal recurso para formar estos adjetivos. De los 25 ejemplos localizados, 7 de ellos no existían en latín sino que son de creación romance, lo que es buena muestra de su crecimiento. ${ }^{10}$ Por otra parte, en algunos casos estamos ante adjeti-

\footnotetext{
${ }^{9}$ Menos productivo por su carácter átono.

${ }^{10}$ Estos adjetivos son: angelical, candeal, cavallar, celestial, mundanal, terrenal y umanal.
} 
vos que no empiezan a usarse en nuestra lengua hasta una época tardía: ${ }^{11}$ así, matrimonial, umanal o mundanal los empezamos a encontrar a fines del XIII y no es hasta principios del siglo XIV cuando se documenta divinal; tampoco he documentado usos de angelical hasta la segunda mitad del siglo XIV. Los primeros ejemplos de añal y cavallar son del $L B A$; marital lo vemos a partir de 1427 y unos pocos años más tarde municipal. Por último, dental no parece entrar en nuestra lengua hasta la última década del XV. Todo ello quiere decir que a los adjetivos en -AL de los primeros tiempos van añadiéndose cada vez más adjetivos de este tipo, algunos por recuperación culta, con lo que se afianza este procedimiento como el más productivo.

Por otra parte, hay otro aspecto de la morfología de estos adjetivos, que me gustaría destacar: mientras que los adjetivos calificativos con frecuencia pueden nominalizarse (bondad, fealdad, teatralidad ...) los relacionales, según Bosque (1990, 118; 1993, 18s.), no pueden hacerlo, al menos con la lectura relacional. En español antiguo, sin embargo, la situación era un tanto diferente ya que encontramos, aunque sea solo de forma esporádica, casos de nominalización formal de adjetivos relacionales. Ocurre esto con el sufijo -IDAD y puede deberse en parte a la mayor amplitud de este sufijo, que presenta menos restricciones. Un caso que me ha llamado especialmente la atención es el del sustantivo de herencia latina carmalidad (< CARNALITAS, -ATIS). Este sustantivo ha ido desapareciendo paulatinamente, así, mientras que hasta el siglo XVI es relativamente frecuente, el CORDE solo presenta dos documentos en el XVII y uno en el XVIII, para desaparecer definitivamente a partir de 1800. Es de destacar, no obstante, que todavía aparece recogido en el $D R A E$, pese a su mínimo uso en comparación con su frecuencia en español medieval: ${ }^{12}$

1. «y acometiéndole por diferentes partes ambición, carnalidad, y otros vicios desenfrenados» (1612-1625, Fray Juan Márquez, El gobernador cristiano).

O fijémonos en el siguiente caso, también inexistente en la actualidad:

1. «como ciudadanos - \& ya lur lengua barbareaua por la extraniedat,- \& aquellos qui eran en seruitut auielos ...» (1379-1384, Juan Fernández de Heredia, Vidas paralelas de Plutarco, III).

Vemos, por tanto, que estos adjetivos comienzan, poco a poco, a presentar una serie de restricciones - que luego veremos también en el nivel sintác-

${ }^{11}$ No estoy diciendo, ni mucho menos, que todos sean tardíos ya que, por ejemplo, campal está documentado ya en el año 1100, mortal, spirital, terrenal, infernal o real se encuentran en textos de la primera mitad del siglo XIII, y carnal y criminal aparecen en la obra de Alfonso X. Por su parte, candeal, celestial, molar, natural, obispal, seglar y comunal se localizan también en torno a la mitad del siglo XIII.

${ }^{12}$ Este sustantivo parece formado en el español actual sobre el adjetivo calificativo y no ya sobre el relacional. Sobre esta evolución insistiré en el último apartado de este trabajo (cf. Serradilla, en prensa). 
tico -, y reducen sus posibilidades de sustantivación morfológica. Podemos decir que, en general, en español antiguo una base podía admitir más sufijos que en el español actual; esto puede tener que ver con el hecho de que no existía aún tanta fijación de piezas léxicas.

Otra propiedad de estos adjetivos es que, normalmente, no admiten la sufijación apreciativa, propia de los adjetivos valorativos: grandecito, malillo, buenecillo, pequeñito ... En este sentido, estos adjetivos parecen haber seguido una pauta de comportamiento estable a lo largo de la historia ya que es difícil encontrar ejemplos de aumentativos o diminutivos; de hecho en toda la documentación que he manejado solo he localizado dos casos de diminutivo: judiezno (no incluido en la nómina) y serranilla y en este último caso hay que destacar que funciona como sustantivo:

1. «el ninno jud(ï)ezno» (Berceo, Milagros, 357b)

2. «por essa serraniella menos non se preciava» (1252-1257, Berceo, Poema de Santa Oria).

En cuanto a la morfología, se observa, pues, que estos adjetivos presentan características similares a lo largo de la historia:

a) se crean a partir de nombres;

b) predominan los mismos sufijos y se observa que el predomino del sufijo -AL va en progresivo aumento;

c) son reacios a admitir diminutivos.

Sin embargo, en los primeros tiempos se admiten todavía nominalizaciones morfológicas que progresivamente dejarán de ser posibles.

En general, hay que destacar también que estamos ante sufijos que presentan una morfología transparente pero hay casos como los citados divino, ageno, seglar ... donde se da una pérdida de transparencia no solo morfológica sino también fonética. Por ejemplo, en un caso como ageno los hablantes no son conscientes ya de su origen - ALIENUs 'de otro' - y esto tendrá repercusiones sintácticas y semánticas que iré apuntando a lo largo de este trabajo. $^{13}$

${ }^{13}$ De hecho, un adjetivo como ajeno plantea problemas de lectura. En origen tiene un claro valor relacional (del lat. ALIENUS, de ALIUS, otro) tal y como recogen las acepciones 1 y 2 del $D R A E$ : «Perteneciente a otra persona»; «De otra clase o condición». Este es el valor principal de la mayoría de los ejemplos analizados pero ya desde antiguo este adjetivo comienza a presentar otros valores que permiten una lectura como valorativo (DRAE: acepcs. 3 y 4): «Distante, lejano, libre de algo Ajeno de cuidados»; «Impropio, extraño, no correspondiente Ajeno a su voluntad». Después en español este adjetivo ha adquirido nuevos valores como 'que no tiene conocimiento de algo, o no está prevenido de lo que ha de suceder', que aún no se localizan en los textos analizados. 


\subsection{Sintaxis de los adjetivos relacionales en español antiguo}

En primer lugar, quiero hacer una aclaración en torno a la función sintáctica de los sintagmas en los que aparecen estos adjetivos, que me servirá para enlazar con su posición respecto al sustantivo al que modifican. Podemos decir que los adjetivos relacionales acompañan a nombres que funcionan como complementos con o sin preposición o como sujetos; si bien esta última función es menos frecuente. De hecho, todos los adjetivos que he analizado pueden aparecer junto a un nombre que funciona como complemento (100\%), pero no todos ellos están documentados acompañando a un nombre que funciona como sujeto (solo el 78\% - 39 adjetivos). Sin embargo, no es este el aspecto en que me parece más significativo sino el hecho de que, mientras que, cuando el adjetivo entra en un sintagma que hace las funciones de complemento, de los adjetivos analizados el 96\% (48) aparece pospuesto en alguna ocasión, frente al 72\% (36), que puede aparecer antepuesto, en el caso de que hablemos de la función de sujeto las proporciones varían notablemente. Así de los 50 adjetivos que estamos estudiando, solo 39, como acabo de presentar, aparecen como sujetos; de estos 39 aparecen pospuestos al nombre 37 , lo que supone un $94,87 \%$ (y un $74 \%$ del total de los adjetivos analizados) - «aun en aquel tiempo en que el linaje humano era como nesciuelo a manera de mozuelo» (Fray Hernando de Talavera, Católica impugnación del herético libelo maldito ...) -; sin embargo, la proporción de adjetivos que pueden anteponerse al nombre baja notablemente y solo encontramos 18 adjetivos que se documentan en esa posición, lo que supone un 46,15\% (y un $36 \%$ del total) - «assi como el humano entendimiento coje lo uno despues de lo otro» (1494, Fray Vicente de Burgos, Traducción de El Libro de Proprietatibus Rerum) - . Esta situación nos conduce a algunas reflexiones ya que esto nos puede indicar que la posición del adjetivo está relativamente determinada - o, al menos, presenta alguna restricción - por la función sintáctica. Hay una correlación estadística entre la colocación del adjetivo y su función sintáctica.

En este punto, quizás sea importante también hacer una referencia al orden de palabras en español ya que, habitualmente, la primera posición la ocupa el tema, que suele ser el sujeto, y dentro de este, el elemento temático suele ser el sustantivo y no el adjetivo, por esa razón es más difícil observar la anteposición cuando el adjetivo está en un sintagma sujeto. Se trata, en todo caso, de una propuesta que ha de ser analizada en trabajos posteriores. Desde una visión sincrónica del español contemporáneo es posible afirmar que, mientras que el adjetivo antepuesto representa una cualidad ya conocida, el adjetivo pospuesto constituye un elemento nuevo que aporta información; como a continuación veremos, no es este siempre el caso del español medieval en lo que respecta al orden de los adjetivos relacionales y el nombre al que acompañan ya que este orden es mucho más flexible y un adjetivo relacional antepuesto es igualmente informativo. Lo que quiero destacar es que, independientemente de la información que pueda aportar el adjetivo, al ser el nombre 
el elemento más conocido, menos informativo, es este el que tiende a colocarse en la posición inicial de la frase y por esta razón encontramos el adjetivo antepuesto en posición inicial con una frecuencia mucho menor. Como digo, sin embargo, es una línea en la que es necesario seguir investigando.

En la siguiente tabla se detallan los adjetivos que funcionan en alguna ocasión modificando a un nombre sujeto y sus posibilidades de colocación:

Tabla 2: Adjetivos que pueden aparecer en un sintagma sujeto (antepuestos y pospuestos)

\begin{tabular}{|c|c|c|}
\hline adjetivo en sn-sj & antepuesto & pospuesto \\
\hline ageno & sí & no \\
\hline angelical & sí & no \\
\hline angélico & sí & sí \\
\hline añal & no & sí \\
\hline ballestero & sí & sí \\
\hline carnal & sí & sí \\
\hline castellano & no & sí \\
\hline cavallar & no & sí \\
\hline celestial & sí & sí \\
\hline criminal & no & sí \\
\hline cristiano & no & sí \\
\hline divinal & sí & sí \\
\hline divino & sí & sí \\
\hline elegiaco & no & sí \\
\hline extraña & no & sí \\
\hline estrellero & no & sí \\
\hline francés & sí & sí \\
\hline greciano & no & sí \\
\hline griego & no & sí \\
\hline humano & sí & sí \\
\hline marino & no & sí \\
\hline matrimonial & no & sí \\
\hline molar & no & sí \\
\hline morisco & no & sí \\
\hline mortal & sí & sí \\
\hline mundanal & sí & sí \\
\hline mundano & sí & sí \\
\hline municipal & no & sí \\
\hline natural & sí & sí \\
\hline obispal & no & sí \\
\hline público & sí & sí \\
\hline real & no & sí \\
\hline romano & no & sí \\
\hline rústico & no & sí \\
\hline serrano & no & sí \\
\hline spirital & sí & sí \\
\hline toledano & no & sí \\
\hline umanal & sí & sí \\
\hline ynfernal & sí & sí \\
\hline TOTAL 39 de 50 & $\begin{array}{r}18-36 \% \text { del total } \\
46,15 \% \text { de } 39\end{array}$ & $\begin{array}{r}37-74 \% \text { del total } \\
94,87 \% \text { de } 39\end{array}$ \\
\hline
\end{tabular}


En la siguiente tabla, que coincide con la tabla 5, se incluyen todos los adjetivos que se pueden anteponer a un nombre que funciona como complemento con o sin preposición. No presento los casos de posposición ya que son la totalidad de adjetivos analizados excepto elegiaco. ${ }^{14}$

Tabla 3: Adjetivos que pueden aparecer antepuestos modificando a un nombre que funciona como complemento

\begin{tabular}{|l|l|l|l|l|}
\hline ageno & angelical & angélico & añal & ballestero \\
\hline candeal & carnal & castellano & celestial & comunal \\
\hline criminal & divinal & divino & elegíaco & extraña \\
\hline francés & greciano & griego & humano & marino \\
\hline marital & matrimonial & mortal & mundanal & mundano \\
\hline natural & obispal & público & real & romano \\
\hline rústico & seglar & spirital & terrenal & umanal \\
\hline ynfernal & & total: 36 & & $72 \%$ \\
\hline
\end{tabular}

Una vez apuntados estos primeros datos y estas breves reflexiones, quiero llamar la atención sobre otro punto que me parece muy significativo: el hecho de que estos adjetivos provengan de nombres, no solo formalmente sino también sintácticamente, en el sentido de que cubren la expresión de una relación antes cubierta por un nombre en genitivo, traerá como consecuencia el que estemos ante adjetivos muy cercanos a los nombres en su comportamiento sintáctico. Sobre este punto, insiste Bosque (1993), quien llega a hablar de «pseudo-adjetivos» o categorías cuasinominales, aunque este autor contempla únicamente la sincronía y no tiene en cuenta que estamos ante una situación que se justifica fácilmente por la evolución diacrónica. ${ }^{15}$

\subsubsection{La colocación de los adjetivos relacionales}

Aunque en español actual la posición de los adjetivos relacionales aparece fijada tras el nombre al que modifican y, de hecho, se usa como criterio distinguidor (Bosque 1993; Demonte 1999; Almela 2000, quien presenta un exce-

14 En el caso de este adjetivo la documentación es escasa y, aunque en los textos medievales no encontremos la posposición, sí hay algún ejemplo de épocas posteriores: «por las quales razones quise componer en verso elegiaco esta confection hecha a manera de porcion» (1586, Francisco Núñez de Coria, Tratado del uso de las mujeres).

15 Fábregas (2005) va más allá en la clasificación de estos adjetivos y cuestiona el que los relacionales puedan ser incluidos dentro de la categoría de los adjetivos. Para este autor, estaríamos ante «sustantivos encubiertos que aparecen realizados como adjetivos para ser legitimados como argumentos» (Fábregas 2005, 195). En este trabajo presentaré las múltiples similitudes entre adjetivos relacionales y nombres en lo que a la sintaxis se refiere, pero no me atrevo a llegar tan lejos como lo hace Fábregas. 
lente estado de la cuestión, entre otros), en la antigüedad su posición no estaba aún fijada y podían aparecer antepuestos, bien por cuestiones rítmicas o de rima, bien por latinismo, bien por otras razones (García González 1990, Lapesa 1975/2000). En todo caso, lo más frecuente es que los adjetivos relacionales aparezcan pospuestos y así ocurre en la mayoría de los casos, más de un $90 \%$ de las apariciones en toda la época medieval. Propongo, a continuación, una muestra de adjetivos pospuestos:

1. «\& lo vinjeron a conosçer \& adorar por rreuelaçion angelical luego commo nasçio» (1453-1467, Alfonso de Toledo, Invencionario).

2. «Linda graçiosa real, clavellina angelical la joya que por señal atendí» (1379-1425, Alfonso de Villasandino, Poesías [Cancionero de Baena]). ${ }^{16}$

3. «por esto los theologos afirman que en las espeçies angelicas no ay algunos individuos, mas cada angel ha ...» (1494, Fray Vicente de Burgos, Traducción de El Libro de Proprietatibus Rerum ....). ${ }^{17}$

4. «e aquel movimiento del solar curso añal, e dónde vino el linagge de los ombres» (1427-1428, Enrique de Villena, Traducción y glosas de la Eneida. Libros I-III). ${ }^{18}$

5. «\& pusieron sobre el muro peones ballesteros que guardassen» (1270-1284, Alfonso X, Estoria de España, II).

6. «nec cavalcatam nec hostem, et si forte batallam campalem vel sitium de castello fecerimus sequatis no ...» (1100, Fueros concedidos por Pedro I a los pobladores de Barbastro) ${ }^{19}$

7. «... y triste con tu muerte le heziste dexar las cosas campales; yervas nos davan malvadas las sembradas ...» (1496, Juan del Encina, Traducción de las Bucólicas de Virgilio). ${ }^{20}$

8. «de yerua putera \& mesclalo con farina de trigo candeal que sea çernjda .viij[o]. vezes» (1471, Juan Enríquez, Secretos).

${ }^{16}$ En realidad, este ejemplo constituye una excepción, ya que es el único localizado en el que el adjetivo parece ser valorativo y no relacional, es decir, en este caso no expresa 'de ángeles' sino 'como un ángel, bella'.

17 Obsérvese el siguiente caso de doble adjetivación: «de la ssanjdat de la esçelente perssona angelica del ssennor arçobispo» (1300-1400, Estéfano de Sevilla, Visita y consejo de médicos). El adjetivo valorativo modifica al bloque formado por (el sustantivo + el adjetivo relacional).

${ }^{18}$ No he tenido en cuenta para mi análisis el adjetivo solar, que aparece en este ejemplo, pero quiero llamar aquí la atención sobre su anteposición, extraña en la antigüedad e imposible en la actualidad. En este caso se trataría claramente de un adjetivo relacional argumental (que materializa uno de los argumentos del adjetivo). No me detengo, sin embargo, en la diferencia entre adjetivos relacionales clasificativos y relacionales argumentales, pues no parece tener relevancia para su sintaxis en español medieval. En todo caso, para una mayor profundización en la clasificación de los adjetvos relacionales argumentales conviene acudir al detallado análisis de Luis Santos Ríos (2000).

${ }^{19}$ En este caso batalla campal es una fórmula estereotipada que he localizado al menos en 200 ejemplos.

${ }^{20}$ Es este el único ejemplo localizado en el que campal tiene el significado 'del campo'; obsérvese que es un ejemplo muy tardío. 
9. «que incitó a la donzella, dormiendo, a aquel acto carnal e así se engendró Merlín» (1400-1498, Anónimo, El baladro del sabio Merlín con sus profecías). ${ }^{21}$

10. $« \&$ tornar los en lengua castellana. a laudor \& a gloria del nombre de dios» (1254-1260, Anónimo, Judizios de las estrellas).

11. «otrosy, de ferrar una ferradura cavallar de las de la montaña, a tres mrs. iii» (1462, Anónimo, Arancel de precios y salarios de Cuenca).

12. «tanbien de la vida celestial cuemo de la vida temporal» (1256, Anónimo, Orden de traducción. Documentos de Alfonso $X$...).

13. «mucho a vuestro seruiçio e a prouecho e bien comunal delos vuestros rregnos e delos vuestros vasallos» (1393, Cortes de Madrid).

14. «pero dezimos que todo pecado criminal es mortal, mas non todo mortal es criminal» (1325, Pedro de Cuéllar, Catecismo).

15. «Yten, dexamos para redención de cautivos cristianos de tierra de infieles tres mil ducados» (1491-1516, Alonso de Santa Cruz, Crónica de los Reyes Católicos).

16. «la vna es por vía de enxerimiento dental, asý que el vn diente de la vna parte entre en ...» (1495, Anónimo, Traducción de la Cirugía Mayor de Lanfranco).

17. «devemos catar en él la reverençia de la fermosura divinal» (1325, Pedro de Cuéllar, Catecismo).

18. «vivo fincava, que non prendié nul mal, la natura divina, la raíz spirital» (1228-1246, Gonzalo de Berceo, Del sacrificio de la misa).

19. «Elegi. son versos de miserias. El carmen elegiaco se dize que su son perteneçe alos afligidos» (1490, Alonso de Palencia, Universal vocabulario en latín y en romance).

20. «casara con puta manifiesta. o con mugier estranna \& uil. o lisiada. o sierua. o enferma» (1254-1260, Anónimo, Judizios de las estrellas).

21. «E quando tornó de allá, contóle aquell judío estrellero todo lo que conoçiera en la nasçiencia de ...» (1467-1475, Pedro de Escavias, Repertorio de príncipes de España).

22. «En ella halló un cosario francés, con una nao francesa y dos navíos que había tomado de castellanos» (1498, Anónimo, Relación del Tercer Viaje de Colón).

23. «les tornasse mano; mas por toda la pérdida el rëy greçiano tanto dava por ello como por un tavano» (1240-1250, Anónimo, Libro de Alexandre).

${ }^{21}$ Estamos ante un adjetivo de gran uso en la época y sirve para acompañar a sustantivos muy variados: mugier, pariente, hermano, padre, persona, sobrino, hermano, primo, factura, obra, uso, fecho, acceso, cosa, gloria, condiçion, conjunçion, desonestad, laciuia, pecado, saber, inclinacion, conversaçion, suziedat, debdo, costumbre, cogniçion, ayuntamiento, facilidad, vileza, deleite, correpçion, presunçion, entendimiento, cognoscimiento, enfermedat, seso, consorcia, adulterio, descanso, plazer, viçio, coraçon, parte y fuerça. Podemos decir, por tanto, que en esta época el adjetivo tiene mayor alcance, en el sentido de que presenta un mayor número de combinaciones sintagmáticas. Esto no obsta para que, tal y como se apunta en el diccionario de Bosque (2004), siga siendo un adjetivo que hoy en día admite la combinación con una gran cantidad de sustantivos. 
24. «Et dixieron los philosophos griegos que el nombre de ercules era compuesto de dos ...» (1385, Juan Fernández de Heredia, Gran Crónica de España, I).

25. «Esto quería dezir que el cuerpo humano, cuando muere, luego comiença a efundir» (1427-1428, Enrique de Villena, Traducción y glosas de la Eneida. Libros I-III).

26. «Et hemos sperança que por una batalla marina faremos çessar nuestros enemigos» (1384-1396, Juan Fernández de Heredia, Traducción de Tucídides).

27. «y representa con su santidat a los lechos maritales» (1425-1450, Juan Rodríguez del Padrón, Bursario).

28. «lo que deius dize quanto a la fe et a la lealdat matrimonial posada por Hugo de Sant Victor» (1376-1396, Juan Fernández de Heredia, Libro de actoridades (Rams de flors)).

29. «E con este conssejo. ssera la rregion molar conseruada con la ayuda djujnal» (1300-1400, Estéfano de Sevilla, Visita y consejo de médicos).

30. «Los omnes codiciosos del haver monedado que por ganar riquezas non dubdan fer pecado» (1236-1246, Gonzalo de Berceo, Los signos del juicio final). ${ }^{22}$

31. «al ssennor non le conujene comer njnguna carne montesa por que toda es mala» (1300-1400, Estéfano de Sevilla, Visita y consejo de médicos).

32. «Allí sale gritando la guitarra morisca, de las bozes aguda e de los puntos arisca» (1330-1343, Libro de Buen Amor).

33. «Tod omme que firiere et non fore ferida mortal, enna prision iaziendo, de fiadores ...» (1234-1275, Fuero de Cáceres $){ }^{23}$

34. «que han de estar apartados de las negoçiaçiones mundanas y ocupados en los divinos ministerios» (1474-1500, Antonio de Villalpando, Razonamiento de las Reales Armas de los Católicos Reyes).

35. «Libro VIII de los Morales, dize que la prosperidat mundanal ligua los piedes del hombre»(1376-1396, Juan Fernández de Heredia, Libro de actoridades (Rams de flors)).

36. «todo derecho e ley canónyco e çevil e municipal, fueros e hordenamientos, usos e costunbres» (1448, Anónimo, Carta de obligación de pleitos).

37. «que no puede hombre fuir el dolor natural, así como el que viene por muerte de sus parientes» (1300-1305, Anónimo, Libro del cavallero Cifar).

38. «por esso manda el derecho que en cada una eglesia obispal. aya maestro de gramatica» (1256-1263, Alfonso X, Siete Partidas).

39. «a canpana tañida segund lo han de uso a conçejo publico con el señor corregidor Alonso Martinez» (1498-1501, Libro de Acuerdos del Concejo Madrileño).

${ }^{22}$ Este adjetivo prácticamente constituye una fórmula fija con «aver»; así lo recoge, de hecho, la última edición del diccionario académico en la entrada «haber ${ }^{2} »$.

${ }^{23}$ Quiero destacar que en los casos de posposición el adjetivo mortal es un adjetivo relacional referido a la muerte, mientras que este valor se pierde, en ocasiones, como veremos más adelante, cuando va antepuesto, pasando así a convertirse en calificativo. Se trata de una especialización del adjetivo dependiente de la posición, que no se observa aún en los ejemplos medievales. 
40. «XIII Del que apuerta agena cagare. Del que puerta agena apedreare. Del que cuernos sobre casa agena ...» (1218-1250, Fuero de Zorita de los Canes).

41. «devo por precio numnado L moravedís de moneda real» (1233, Anónimo: Carta de venta). ${ }^{24}$

42. «despidiósse Estevan de las yentes romanas» (1246-1252, Gonzalo de Berceo, Los Milagros de Nuestra Señora).

43. «\&el que se desposare con moça rustica o aldeana dele diez mr.; \& ala bifda çinco mr.» (1284-1295, Anónimo, Fuero de Cuenca) ${ }^{25}$

44. «que non nos vala ni que seamos oydos en Corte seglar, ni en Sancta Eglesia» (1320, Anonimo, Cambio de una pieza por otra, ambas en Murillo de ...).

45. «salvo por los pechos que pecharen los cavalleros serranos; e, si fuer quito a los serranos» (1389, Anónimo, El consejo real sentencia a favor de los pecheros abulenses).

46. «el padrino es padre de su afijado por nascimiento spirital. Esso mismo dezimos de las madrinas» (1256-1263, Alfonso X, Siete Partidas).

47. «... e fiço mayoral; non negó su tributo al señor terrenal» (12361246, Gonzalo de Berceo, Loores de Nuestra Señora).

48. «Iudgo en letra ladina, ca enante yera en letra toledana, e no lo podía todo omne leer» (1266, Sentencia [Documentos de la Catedral de León]).

49. «que la ley umanal tiene una imagen de la ley divinal» (1454-1457, Rodrigo Sánchez de Arévalo, Suma de la política).

50. «Muchos aborrexen la pena eternal o infernal, mas yo digo que mayor pena es el caymiento» (1376-1396, Juan Fernández de Heredia, Libro de actoridades (Rams de flors)).

La posposición parece ser la colocación natural de este tipo de adjetivo; así, por ejemplo, de los 160 casos documentados en el CORDE del adjetivo toledano no hay ningún ejemplo de anteposición. Lo mismo ocurre con morisco, del que he documentado varios cientos de apariciones sin que haya ningún caso de anteposición. Asimismo, dental, campal, cavallar, carnicero, cristiano, estrellero, molar, montesa, municipal, monedado, palaciano y serrano solo aparecen pospuestos.

Tabla 4: Adjetivos pospuestos

todos los adjetivos analizados

${ }^{24}$ Es necesario hacer una referencia a real < REGALIS, que se refiere únicamente a lo relativo al rey y no presenta el valor más empleado hoy de 'existente, verdadero' frente a 'falso, virtual', procedente de REALIS.

${ }^{25}$ Obsérvese que el adjetivo rústico tiene desde antiguo dos valores. El que aquí nos interesa es el relativo al campo, ya que con él funciona como adjetivo relacional mientras que el valor de 'necio, poco pulido ...' convierte al adjetivo en valorativo. Este doble valor responde a la existencia en latín de dos términos: Rusticus, -A, -UM 'del campo', 'simple, ingenuo' y Rusticus, -I 'campesino, aldeano'. Véase el siguiente ejemplo: «o labra enel aldea. y esta ende. assi que rustico o es obrero o ombre no polido» (1490, Alonso de Palencia, Universal vocabulario en latín y en romance). 
Debo, sin embargo, hacer una serie de matizaciones ya que en español medieval son también relativamente frecuentes, como ya he avanzado, los casos de anteposición, aunque siempre con un número de apariciones mínimo en comparación con los anteriores. Como nos recuerda Lapesa (1975/2000, 210s.), en latín el adjetivo se anteponía al nombre que modificaba excepto cuando el sustantivo era monosílabo (vir fortis) o cuando el adjetivo derivaba de un nombre propio (populus Romanus) pero «Tal estado de cosas hubo de cambiar considerablemente en latín vulgar, donde la posposición, excepcional en el clásico, dejó de serlo». ${ }^{26}$ Es este último el orden más frecuente en español, no obstante, en algunos casos un mismo adjetivo puede anteponerse o posponerse sin que se dé ningún cambio significativo y también, en ocasiones, se dan casos de anteposiciones por razones métricas, anteposiciones formularias (Romano Pontífice) ${ }^{27}$ o anteposiciones de carácter literario, sobre todo en el siglo XV cuando el esfuerzo latinizante es mayor, lo que provoca que el orden de este tipo de adjetivo no tenga la fijación que encontramos en el español actual. Además, es importante señalar que a diferencia de lo que ocurre hoy en día, la anteposición no trae consigo normalmente una recategorización en valorativo. De hecho, en muchos de los casos que presentaré, se hace evidente que la tesis de Gröber sobre la colocación del adjetivo no parece cumplirse: «El adjetivo calificativo pospuesto determina o distingue intelectualmente; antepuesto, atribuye al sustantivo una cualidad subjetivamente valorada» (apud Lapesa 2000, 211).

Quiero señalar, sin embargo, que los ejemplos analizados pertenecen a textos literarios en los que la anteposición aparece motivada, en muchos casos, por necesidades métricas y de rima y, a menudo, se justifica por los esfuerzos latinizantes del siglo XV, donde eran frecuentes los hipérbatos muy forzados; o a textos jurídicos con frecuentes fórmulas fraseológicas. Por ello no podemos olvidarnos de que estamos ante una lengua especial, que busca el extrañamiento y puede dar lugar a distorsiones de la lengua más habitual. Ante esta realidad, debemos admitir que solo estamos prestando atención a la lengua de un determinado grupo sociolingüístico y que, seguramente, no podemos extrapolar nuestras conclusiones a la variedad coloquial más generalizada.

Una vez hechas estas matizaciones, detengámonos ahora en aquellos adjetivos que presentan la posibilidad de aparecer antepuestos. Muchos de estos adjetivos tienen una base culta lo que, como se irá viendo a continuación, quizás explique la tendencia a la anteposición.

1. «a ti, Señora mía; en ciella te trobó, sin carnal compañía, dulzment' te saludó» (1236-1246, Gonzalo de Berceo, Loores de Nuestra Senora).

${ }^{26}$ También el genitivo que modificaba a otro nombre podía aparecer ante el nombre con el que se relacionaba.

${ }^{27}$ Son casos en los que casi se podría hablar de colocaciones o de compuestos sintagmáticos, ya que estamos ante estereotipos literarios o fórmulas fijadas, donde la relación entre los componentes es muy estrecha. 
2. «porquel del mayor y mejor rey cristiano es su carnal primo segund que sabemos aqueste es osorio que ...» (1498, Francisco López de Villalobos, Sumario de la medicina con un compendio sobre las pestiferas).

3. «en el seglar lenguaje» (Mil. 321b).

4. «castigo en su manera, bien como la rapossa en agena mollera» (1330-1343, Libro de Buen Amor) ${ }^{28}$

5. «\& so tu uezino \& no uengo como estranyo de agena tierra por demandar te tu fija \& semblantment» (1385, Juan Fernández de Heredia, Gran Crónica de España).

6. «grand manadilla; sus tovillos mayores que de una añal novilla» (1330-1343, Libro de Buen Amor).

7. «e de diversos marcos: trayán armas muy fuertes e ballesteros arcos» (1330-1343, Libro de Buen Amor).

8. «ca por la mayor parte todos los trasmontanos. de comunal postura establesçieron. que tolliessen ...» (1270-1284, Alfonso X, Estoria de España, II).

9. «... que es reconçiliada con el agua gregorial con obispal mano, segúnd por nuestra culpa asaz a menudo ...» (1427-1428, Enrique de Villena, Traducción y glosas de la Eneida. Libros I-III).

10. «El ángel questo dezía, angelical muchedumbre se llegó a su conpañía» (1467-1482, Frey Íñigo de Mendoza, Coplas de Vita Christi).

11. «y es tanta la differençia del angelico entendimiento al humano» (1494, Fray Vicente de Burgos, Traducción de El Libro de Proprietatibus Rerum).

12. «Cuando plogo a Christo, al celestial Señor, finó Sant Illefonsso» (1246-1252, Gonzalo de Berceo, Los Milagros de Nuestra Señora). ${ }^{29}$

13. «porque, asi como el cuerpo que es conpuesto de la terrenal materia ha menester manjares a el conformes» (1474-1500, Antonio de Villalpando, Razonamiento de las Reales Armas de los Católicos Reyes).

14. «Comiénçase a enamorar de Dios e desechar el mundano amor, siquiere viçioso» (1427-1428, Enrique de Villena, Traducción y glosas de la Eneida. Libros I-III).

15. «... en la memoria fenescer con ella todas las mundanales cosas?» (1482-1492, Garci Rodríguez de Montalvo, Amadís de Gaula, libros I $y$ II).

16. «\& uino en espanya. \& priso tierra enla marina Ribera de Espanya» (1385, Juan Fernández de Heredia, Gran Crónica de España, I).

17. «tú que con lágrimas nos profetizas, las maritales regando cenizas» (1444, Juan de Mena, Laberinto de fortuna).

${ }^{28}$ En este caso, así como en otros de los presentados, es evidente que la anteposición es debida a necesidades de la rima.

${ }^{29}$ Celestial puede anteponerse al nombre al que acompaña y en este caso se trata de una construcción bastante frecuente. Destaco que, de todas formas, en todos los casos encontrados el adjetivo es claramente relacional; solo, quizás, en el siguiente ejemplo pueda leerse como valorativo: «gracia / \& plazible gesto de todo el rostro: la celestial risa / \& los diuersos mouimientos dela cara» (1494, Anónimo, Mujeres ilustres). Obsérvese que estamos ante un ejemplo muy tardío. 
18. «ansi como paresçe en el matrimonial ajuntamiento» (1440-1455, «El Tostado», Alonso Fernández de Madrigal, Libro de amor e amicicia).

19. «por que las spiritales cosas son mas nobles que las temporales» (1256-1263, Alfonso X, Siete Partidas) ${ }^{30}$

Veamos ahora algunos usos antepuestos de mortal. En este caso, parece ser que cuando se da esta posición el adjetivo es de carácter valorativo básicamente. Se trata, pues, de uno de los pocos casos en los que el orden puede determinar la categoría del adjetivo:

20. «por la su sancta gracia que nos libre de mal, del mortal enemigo, del fuego infernal» (1228-1246, Gonzalo de Berceo, Del sacrificio de la misa).

21. «pariste sin pena; por ti s' fue afloxando la tan mortal cadena, por ti cobró logar la oveja centena» (1236-1246, Gonzalo de Berceo, Loores de Nuestra Señora). ${ }^{31}$

22. «aun nos averá mester. Mas sy él sopiera el mortal dapño quele feziera desu fija, quele mató» (1300-1325, Anónimo, Cuento muy fermoso de Otas de Roma). ${ }^{32}$

Los gentilicios van habitualmente pospuestos, aunque es también posible encontrar algunos casos de anteposición en el español medieval.

23. «si la virtud de los portugueses sobrepujase a los castellanos peones armados que allí venían» (1487-1488, Diego de Valera, Crónica de los Reyes Católicos).

24. «et de su ley; has fallescido a tu Rey, vas con la griega Rapina; con la Caua castellana te sentarás a ...» (1407-1463, Juan de Tapia, Sin título [Cancionero de Estúñiga]).

25. «E ansí lo fallará quien las romanas estorias leyere» (1450-1455, Fernán Pérez de Guzmán, Generaciones y semblanzas).

26. «de la Reyna donna Costança. que era francesa mugier deste Rey don Alffonso» (1270-1284, Alfonso X, Estoria de España, II).

Lo mismo ocurre con otros adjetivos:

27. «E si fuere en signo aqueo; sera por agua. o por enfermedades vmidas. E si non ouiere ayuda de las fortunas; significa que sera lisiado de cuerpo. o sera ciego. o uiuira en estranna tierra» (1254-1260, Anónimo, Judizios de las estrellas).

28. «do se ceban los ángeles del buen candïal trigo» (1246-1252, Gonzalo de Berceo, Los Milagros de Nuestra Señora).

29. «en elegíaco verso cantando» (Juan de Mena, Laber. 840). ción.

${ }^{30}$ De los 136 ejemplos analizados del adjetivo spirital solo 2 presentan la anteposi-

${ }^{31}$ En este caso el adjetivo relacional aparece graduado, característica que, como veremos, en español actual es exclusiva de los adjetivos cualitativos y valorativos. En todo caso, quizás sea posible percibir aquí el inicio del desplazamiento hacia calificativo, que no se observa en otros de los ejemplos citados. Por otra parte, la anteposición viene motivada por la rima.

${ }^{32} \mathrm{El}$ adjetivo de este ejemplo tiene, sin embargo, un claro valor relacional, que también se observa en otros ejemplos. 
30. «... sí una derecha raçón: que, fecha la conclusión en criminal acusaçión» (1330-1343, Libro de Buen Amor).

31. «caualleros de cueros crudos e fust a manera de rusticos calceros, los quales los habitadores de la ...» (1385-1396, Anónimo, Obra sacada de las crónicas de San Isidoro, de Don Lucas).

32. «Et yo Iohan Periz de Ualgannon, publico notario do Ffrias, a ruego del dicho don Pero» (1270, Anónimo, Carta de venta).

33. «Merçed vos pido a vos, mio natural señor» (Cid, 2031). ${ }^{33}$

34. «El natural querer de padre le rasgava las entrañas» (1499, Anónimo, La historia de los nobles caballeros Oliveros de Castilla y ...).

35. «en todas las otras cosas que ala justiçia e a su real ofiçio perteneçe, e que Nuestro Señor permitió» (1492, Anónimo, Relación de la cuchillada que se dio al Rey).

36. «\& fue muerto enla cruz por Saluar el umanal linaje» (1293, Anónimo, Castigos).

37. «Mas ala fin por copdiçia \& por humano engenyo ellos quisieron sacar el oro» (1385, Juan Fernández de Heredia, Gran Crónica de España, I).

Ynfernal como adjetivo relacional puede aparecer antepuesto:

38. «a los miserables griegos y asimesmo dio al infernal huerco las ánimas fuertes de los señores» (1442, Juan de Mena, Homero romanzado).

Aunque, en algunos casos, ya en el siglo XV, al igual que ocurre cuando va pospuesto, puede aparecer también como adjetivo valorativo con el valor de 'terrible' y no exactamente con el de 'relativo al infierno':

39. «e acorre a ti mesmo e non quieras que con infernal rabia yo aya de fazer aquellas cosas» (1471-1476, Lope García de Salazar, Istoria de las bienandanzas e fortunas).

Un adjetivo singular dentro de los que estamos analizando es divinal ya que en este caso predomina la anteposición. De todas formas, hemos de tener en cuenta que casi todos los ejemplos documentados (a excepción de 16) son del siglo XV y su uso antepuesto obedece, en gran medida, al esfuerzo latinizante del siglo. En todo caso, su uso como relacional parece evidente ya que su significado es 'de Dios', 'relativo a Dios':

40. «la segunda nobleza de los reyes es conocer la divinal verdad, la qual verdad es Dios» (1300-1305, Anónimo, Libro del cavallero Cifar).

El adjetivo divino, por su parte, aparece antepuesto con muchísima frecuencia desde textos muy tempranos. De hecho, hay una importante documentación latina en la que se puede observar la anteposición y que puede servir de modelo en determinadas fórmulas:

41. «... redemptoris nostri. Ego igitur senior Lope Sanchiz divino amore compunctus ac scelerum meorum recordatus» (1075-1124,

${ }^{33}$ En este caso la métrica es determinante para el orden del adjetivo. 
Anónimo, Ofrenda de Lope Sánchez a San Millán del monasterio de Santi...).

42. «bien es dicho que tienen orejas porque reçiben la divina inspiraçion, la qual juzgando desçernen» (1494, Fray Vicente de Burgos, Traducción de El Libro de Proprietatibus Rerum).

Tabla 5: Adjetivos que pueden anteponerse en español medieval ${ }^{34}$

\begin{tabular}{|l|l|l|l|l|}
\hline ageno & angelical & angélico & añal & ballestero \\
\hline candeal & carnal & castellano & celestial & comunal \\
\hline criminal & divinal & divino & elegíaco & extraña \\
\hline francés & greciano & griego & humano & marino \\
\hline marital & matrimonial & mortal & mundanal & mundano \\
\hline natural & obispal & público & real & romano \\
\hline rústico & seglar & spirital & terrenal & umanal \\
\hline ynfernal & & total: 36 & $72 \%$ \\
\hline
\end{tabular}

$\mathrm{Al}$ estudiar estos adjetivos podemos concluir que nos encontramos, de hecho, ante una categoría que no ha asentado aún definitivamente su orden en la frase. Observamos, pues, cómo en español antiguo se da un número importante de casos de anteposición de adjetivos relacionales; es verdad que esta no es, ni mucho menos, la posición predominante y que en muchos de los casos se debe a los esfuerzos latinizantes del siglo XV, pero no todos los ejemplos se explican así, ya que hay algunos casos anteriores donde la presión es menor. En todo caso, no podemos olvidar la importancia que el latín tiene en la escritura medieval y es posible que la anteposición, que encontramos en los textos con tanta frecuencia, no tuviera igual relevancia en la lengua oral y que en esta estuviera más fijado el orden pospuesto, que empieza a ser mayoritario ya en el latín hablado.

La anteposición como posibilidad constructiva va desapareciendo a lo largo de los siglos hasta llegar a la situación del español actual. La categoría del adjetivo permite distinguir dos subtipos: los calificativos y los relacionales; con los datos que tenemos observamos cómo la lengua medieval va gramaticalizando poco a poco el comportamiento de unos y otros.

He realizado un rastreo por textos del español clásico y, si bien en los primeros años del XVI todavía se daba la anteposición, más adelante es difícil encontrarla a no ser en expresiones formularias. Propongo, a continuación, una muestra donde se observan todavía algunos casos de anteposición en la segunda mitad del siglo XVII. Estamos ante textos de carácter moralizante, de tono conservador y arcaizante, con un afán latinizante evidente - uso

${ }^{34}$ En todo caso no debe olvidarse que muchos de los adjetivos analizados solo presentan la anteposición de forma muy esporádica. 
técnico, pues, que supone una variedad diastrática - o procedentes de países americanos o de Filipinas - variedad diatópica precisa, aunque el corpus analizado no es lo suficientemente amplio como para poder extraer conclusiones fiables en este sentido -. No siempre los textos de estas regiones se caracterizan por su mayor conservadurismo, como ya destaqué en uno de mis trabajos (Serradilla 2002), pero en este caso, sí parece que podemos encontrar usos más arcaicos; no obstante encontramos también documentación en obras de carácter religioso publicadas en la Península. En otros casos, la posición del adjetivo se debe, simplemente, a necesidades de la rima.

1. «pues aquel daua al cuydado, y estotro dexaua agena prouidencia» (1667, Francisco Combés, Historia de Mindanao y Joló).

2. «triunfante siempre por la azul esfera enarbola su angélica bandera» (1649-1656, Antonio Enríquez Gómez, Sansón Nazareno).

3. «y apostólico celo a presentar al demonio la campal batalla; el cual instigó al capitán portugués» (1698, Fray Gaspar de San Agustín, Conquistas de las Islas Filipinas).

4. «... a las del peregil, para poder passar sin asco la carnal grossería. - Estas otras, aunque vulgares, son ...» (1653, Baltasar Gracián, El Criticón segunda parte).

5. «he considerado el libro compuesto en castellano idioma, trabajado por el doctor Miguel de ...» (1675-1676, Miguel de Molinos, Guía espiritual).

6. «Retórica es que viene del cielo desigualarse los ingenios grandes en una grande obra. No se tenga por culpa lo que es celestial magisterio» (1660, Juan de Zabaleta, El día de fiesta por la tarde).

7. «que es precisa mi partida a procurar que la cristiana doctrina a vuestro convencimiento llegue» (1682, Alejandro Arboreda, El más divino remedio y Aurora de san Ginés).

8. «que por piedad sagrada se libra al fin de la francesa espada» (1670-1700, Miguel de Barrios, Poesías).

9. «... noble y lo bello, con el garvo cortesano, todo el toledano imperio, no le bastó para verme tributario» (1652, Pedro Calderón de la Barca, Cada uno para sí).

10. «... de que tenernos memoria. Doy por fiadores de este humano crédito, fuera del prodigioso cometa» (1690, Carlos de Sigüenza y Góngora, Libra astronómica y filosófica, México).

11. «entrando van: - ¡Tan, talán, tan, tan! Rechine la marina trompa, con el violón; déles tono el bajón ...» (1676-1692, Sor Juana Inés de la Cruz, Villancicos).

12. «... pues a merced lo fué de José, cediendo su matrimonial poder. Pues siendo suya María y siendo ...» (1676-1692, Sor Juana Inés de la Cruz, Villancicos).

13. «avisados con él los hombres, se guardasen de su mortal picadura» (1653, Bernabé Cobo, Historia del Nuevo Mundo).

14. «Asimismo, aunque el natural sentimiento atribula algunas veces, viéndonos ...» (1640-1653, Juan de Palafox y Mendoza, Cartas pastorales, México).

15. «en que consiguiendo el logro de sus deseos, dió público testimonio del fervor amante con que siempre ...» (1683, Carlos de Sigüenza y Góngora, Triunfo parténico, México). 
16. «Previno así mismo la sonora cítara, el rústico rabel, la cortesana arpa, la suave vigüela» (1679, Ana Francisca Abarca de Bolea, Vigilia y octavario de San Juan Baptista).

17. «Cautelóse con la separación de puertas que las mujeres y hombres se dividiesen, no dándose lugar posible a la menor seglar destemplanza» (1653, Gabriel Bocángel, Relación panegírica).

18. «remedauan las delicias del terrenal Parayso» (1662, Anónimo, Gaceta nueva de los sucesos políticos y militares ...).

19. «... el Rey liviano Fizo para tanta saña? ¡A una humanal fraqueza Prevenis fuerzas tamañas!» (1662, Francisco Navarrete y Montañes, Romance que pinta la batalla que don Beltrán ...).

20. «contradicen, con esta accion tan diabolica, y tan infernal doctrina destruien los efectos de su gracia» (1656, Fray Jacinto de la Serna, Tratado de las supersticiones, idolatrías, hechicerías, ritos ..., México).

Se puede concluir, a la vista de los datos de la segunda mitad del siglo XVII que la anteposición del adjetivo relacional va siendo cada vez más escasa, como era de esperar, teniendo en cuenta la situación del español moderno. Este uso, sin embargo, no ha desaparecido por completo y lo encontramos, sobre todo, en verso, donde se da básicamente por necesidades métricas, rítmicas o de rima, o en textos moralizantes, de carácter conservador o arcaizante, especialmente en textos americanos. El tipo de texto, pues, es determinante a la hora de la elección de una u otra construcción.

Por otra parte, en algunos casos, pocos aún, se ve cómo la anteposición trae consigo un paso de relacional a valorativo, igual que en español actual. Quiero señalar que, en todo caso, como ya indicó Alarcos $(1994,83)$, aunque él se refería únicamente a la permutación de la posición de los adjetivos calificativos, «el resultado no perturba la estructura del grupo ni la relación entre sus componentes». Esto resulta evidente sobre todo en el español antiguo donde, por regla general, el cambio de posición ni siquiera tiene relevancia en el significado de la construcción.

\subsubsection{Los adjetivos relacionales como predicados}

Uno de los criterios que normalmente se ha utilizado para diferenciar los adjetivos relacionales de los valorativos es que no pueden ser atributos. Sin embargo, en español actual podemos encontrar, aunque con restricciones a las que luego me referiré, adjetivos de relación que son predicados de oraciones copulativas. Pero lo que aquí más interesa es que en español medieval esta posibilidad es mucho más frecuente y parece que las restricciones son menores. Precisamente esta capacidad de aparecer, en algunos casos, en funciones predicativas es una prueba más de su falta de fijación como clase definida en la antigüedad. Veamos algunos de los documentos con los que contamos. Recuerdo que se recogen aquí distintos tipos de adjetivos: gentilicios, adjetivos que indican procedencia, pertenencia, finalidad, origen, nacionalidad, materia, tipo, grupo, etc., todos ellos incluidos en el subtipo de los relacionales: 
1. «e el terçero entendimiento es carnal \& entiendese por el entendimiento de la carne» (1440-1460, Antón de Zorita, Árbol de batallas, de Honoré Bouvet).

2. «... anguilla ni mucho menos con liebre; trobar en ser carnicero como la ley ordenó; trobar en comer carnero» (1445-1480, Antón de Montoro, Cancionero). ${ }^{35}$

3. «de entremeterse de judgar ningund pleito que sea criminal, asy commo muerte de omme» (1380, Anónimo, Cortes de Soria).

4. «los tales judíos y judías dixesen que querían ser cristianos» (1491-1516, Alonso de Santa Cruz, Crónica de los Reyes Católicos).

5. «ij variedades de versos: el carmen primero que es elegiaco consta primero de verso heroico» (1490, Alonso de Palencia, Universal vocabulario en latín y en romance).

6. «Et el princep Guillem, por aquesto que ell era frances, quiso yrle ayudar \& passo a Brandiz» (1377-1393, Juan Fernández de Heredia, Crónica de Morea).

7. «pues yo soy sin culpa y vos sois humano» (1445-1480, Antón de Montoro, Cancionero).

8. «que guarden el sello e el lecho del acto que es matrimonial, pues una sensiva res muda, brutal» (1445-1480, Antón de Montoro, Cancionero).

9. «et la corupçion uiene de dos razones: la una es natural, la otra es contranatura» (1376-1396, Juan Fernández de Heredia, De secreto secretorum).

10. «\& la tierra es madre suya $\mathrm{E}$ toda su entençion es terrenal enesta guissa cobra la fuerça ...» (1417, Enrique de Villena, Los doze trabajos de Hércules).

Tabla 6: Adjetivos relacionales como predicados

\begin{tabular}{|l|l|l|l|l|}
\hline ageno & carnal & carnicero & castellano & celestial \\
\hline comunal & criminal & cristiano & elegíaco & estrellero \\
\hline francés & griego & humano & matrimonial & morisco \\
\hline mortal & natural & real & rústico & seglar \\
\hline spirital & terrenal & ynfernal & & $46 \%$ \\
\hline
\end{tabular}

Se observa, pues, que casi la mitad de los adjetivos del corpus manejado puede funcionar en ocasiones como predicado, lo que nos obliga a detenernos en algunas reflexiones.

En la lengua actual, considero que podemos concluir que estos adjetivos no pueden funcionar como predicados cuando son claros sustitutos del genitivo latino: *este claustro es universitario ('de la universidad') pero sí lo pueden hacer cuando esto no se da esta relación: yo soy universitaria (¿'de la universidad'? - 'propiedades de la gente que estudia en la universidad'). En

${ }^{35}$ En casos como este y en los de gentilicios (castellano, griego, francés) se ha producido la sustantivación del adjetivo, por lo que no parece que haya ningún problema para que funcionen como atributos. 
el primer caso, solo aparecen en posiciones predicativas si en la oración aparece una contraposición: este claustro es universitario no de monjes, la clínica es dental no ginecológica; véase también el ejemplo citado por Demonte (1999, 159): «podemos decir Esta industria es TEXTIL, y no metalúrgica, aunque *La industria es textil sea una expresión anómala». En la documentación medieval presentada parece existir una mayor libertad constructiva, ya que encontramos casos como 1, donde incluso el adjetivo se parafrasea por 'de la carne', claro sustituto del genitivo; y, por otra parte, aunque hay casos en los que se da la contraposición 9 , también hay ejemplos en los que no hay oposición alguna.

Por otro lado, para Demonte la relación semántica que se establece entre el nombre y el adjetivo, y el tipo sintáctico al que pertenece el nombre modificado son determinantes a la hora de admitir esta construcción. Así, si el nombre es deverbal y el adjetivo es argumento de su red temática, el adjetivo no puede ser predicado (sufrimiento materno - *el sufrimiento es materno; en este caso el adjetivo selecciona el papel temático de Experimentante); sin embargo, cuando el nombre es de objeto (revista, cerámica ...) y la relación que se establece ya no es gramatical, entonces el adjetivo sí puede ser usado predicativamente ya que en estos casos los adjetivos semánticamente son predicados caracterizadores o clasificadores y su sujeto es precisamente el nombre al que modifican (la cerámica es artesanal) (Demonte 1999, 158s.). De nuevo, en español antiguo parece que esta hipótesis puede cuestionarse pues encontramos casos con nombres deverbales como 1 el entendimiento es carnal o 8 el acto que es matrimonial. Son ejemplos que hoy nos resultan agramaticales o al menos presentan contextos más costosos, pero que, como vemos, en español antiguo eran posibles.

No resto valor a estas hipótesis, que pueden comprobarse en español actual, pero la situación es aún más compleja ya que, según Abad (2004), que sigue a Pustejovsky (1995), hay más factores que obstaculizan el que un adjetivo relacional pueda ser predicado, aunque el nombre sea de objeto. Así, Abad hace depender la aceptabilidad o la inaceptabilidad de la construcción de la información que selecciona el adjetivo del nombre al que acompaña. Según esta autora, cuando la información seleccionada se corresponde con el rol o quale bélico (el que hace referencia a la función o la finalidad del objeto), como en *el talento es musical, o con el formal, como en *el paseo es marítimo, el ejemplo cumple la propiedad atribuida a los adjetivos clasificativos y es inaceptable, pero cuando el adjetivo selecciona el rol constitutivo - la revista es musical - o el agentivo - el jabón es artesanal -, el ejemplo es perfectamente aceptable.

Merece la pena detenerse para explicar, aunque sea muy brevemente, en qué consiste la hipótesis de la Estructura de los Qualia en la que se apoya Abad. Se trata de una subteoría del modelo de explicación del léxico propuesto por Pustejovsky (1995), conocido como la Teoría del Lexicón Generativo; según esta teoría, los verbos, nombres y adjetivos contienen un estruc- 
tura compleja capaz de generar gran cantidad de interpretaciones dependiendo del contexto en que aparezcan. Por ejemplo, el adjetivo excelente, predicado de cuchillo o profesor, significa 'que hace muy bien su función', pero predicado de cabellera o persona significa 'que tiene buenas cualidades', lo que se explica, sin necesidad de proponer múltiples acepciones para la palabra excelente, ni múltiples entradas en el lexicón para múltiples excelentes homófonos, si se considera que excelente está capacitado para seleccionar el quale télico de cuchillo o profesor (nombres que contienen información sobre 'para qué sirven') y el quale constitutivo de cabellera o persona (nombres que no contienen información sobre 'para qué sirven' pero sí sobre 'cómo es su constitución interna'). Así, cuando decimos que un adjetivo tiene varias acepciones, lo que estamos sugiriendo es que, en combinación con uno u otro nombre, se predica de una u otra de las informaciones hipotéticamente contenidas en la Estructura de Qualia. En la subteoría de la Estructura de Qualia se distinguen cuatro roles o qualia:

Rol constitutivo: codifica la relación entre un objeto y sus partes, y entre un objeto y la entidad a la que pertenece: tren eléctrico.

Rol formal: contiene información sobre lo que distingue a un objeto de otros dominios: piel facial.

Rol télico: $\quad$ hace referencia a la función y finalidad del objeto: utensilio culinario.

Rol agentivo: establece informaciones relativas a la existencia del objeto, factores que intervienen en su creación: persecución religiosa.

El hecho de que un adjetivo seleccione uno u otro rol va a ocasionar diferencias de significado y va a tener, en ocasiones, repercusiones sintácticas. Así, por ejemplo, si analizamos un caso propuesto por Demonte como es tren eléctrico/central eléctrica, este adjetivo puede significar 'que funciona gracias a la electricidad' cuando acompaña a tren, y, por lo tanto, escoge el rol constitutivo; mientras que, cuando acompaña a central, solo se interpreta como 'que produce electricidad', ya que el rol seleccionado es el télico. Una teoría como esta nos permite explicar muchos de los casos de aparente polisemia de los adjetivos relacionales, al tiempo que nos permite explicar, como hace Abad (2004), por qué unos adjetivos relacionales (los que seleccionan los roles constitutivo y agentivo) pueden funcionar hoy como predicados de oraciones copulativas y otros no (los que seleccionan los roles télico o formal).

En la documentación que presento, sin embargo, encontramos casos como pleito que sea criminal o su entencion es terrenal, donde el adjetivo selecciona el rol formal; o casos como el carmen primero que es elegiaco, donde el seleccionado es el rol télico, lo que parece indicar que la evolución ha supuesto mayor restricción. El que la hipótesis no parezca aplicable a los datos de la diacronía sugiere que, efectivamente, la evolución ha ido hacia unos requisitos más estrictos por lo que el siguiente paso de esta investigación 
bien podría ser indagar sobre cómo se ha producido el cambio en las condiciones de uso. El hecho de que la libertad posicional sea mayor en español medieval se debe a que estos adjetivos aún no han fijado definitivamente todas sus posibilidades constructivas, por lo que pueden aparecer aún en posiciones que posteriormente serán consideradas agramaticales, independientemente de los qualia seleccionados. En realidad, lo interesante del trabajo de Abad, a partir de Pustejovsky, es que permite, en cierto sentido, superar la barrera entre calificativos y clasificativos y basar la separación en otros parámetros, en términos de selección de qualia, y, tal vez, eso sí ayude a entender los datos de la diacronía, aunque, como he señalado, sea un tema pendiente de estudio.

\subsubsection{La gradación de los adjetivos relacionales}

Otra característica de los adjetivos relacionales en español actual es la imposibilidad de ser graduados, en el sentido de que no aparecen en construcciones superlativas o comparativas. No podemos decir *este claustro es muy universitario - este claustro es más universitario que el otro - este es el claustro más universitario o como recoge Demonte (1999, 138): El sabor (*muy) mineral - Este sabor es más mineral que el otro. La situación no es, sin embargo, tan tajante en español antiguo. Como era de esperar, dado lo que hemos visto hasta el momento, nos encontramos con menos restricciones en español antiguo también en este caso. Obsérvese incluso el siguiente ejemplo del español clásico: «que la gente (que es carnalíssima) vendrá luego a caer en la red: pero han de proceder con cautela» (1612-1625, Fray Juan Márquez, El gobernador cristiano).

Obviamente, no es muy frecuente la gradación pero existen algunos ejemplos que nos obligan a cuestionarnos si este es un criterio que resulta útil para la definición de estos adjetivos o si en los casos en que se da la gradación es posible una lectura diferente del adjetivo, es decir, si se da un desplazamiento semántico hacia el área de los valorativos, tal como sucede en español actual donde el adjetivo de una construcción como yo soy muy española o es una costumbre muy universitaria tiene una lectura como valorativo: "poseo las cualidades que caracterizan a una española' o 'es una costumbre característica de las personas que componen la universidad'.

Presento a continuación una muestra de los ejemplos localizados. En algunos de los casos siguientes podemos percibir un uso más calificativo que relacional (4) pero esto no es siempre así ya que, aunque hoy hay adjetivos que deberían ser interpretados como valorativos, como puede ser el caso del ejemplo 7, donde entenderíamos terrenal como 'mundano', aquí significa ‘de la tierra'.

1. «Antes el tal desvarío del saber es muy ageno, ca por mostrarte más lleno te juzgan por...» (1400-1500, VV.AA., Cancionero castellano del s. XV de la Biblioteca Estense). 
2. «de espanto, una crueza de encanto, un hecho muy carnicero. Un hecho muy desabrido» (1467-1482, Frey Íñigo de Mendoza, Coplas de Vita Christi).

3. «que del cielo vino el que virtud tan celestial enseño. justicia tan sobrenatural puso ...» (1499, Gonzalo García de Santa María, Traducción de la Corónica de Aragón).

4. «más que tú de su querella. Amor Pues estás tan criminal, hablar quiero con sossiego por que no ...» (1470-1480, Rodrigo de Cota, Diálogo entre el amor y un viejo).

5. «e quel ánima es otra cosa muy más divina quel armonía? Respondió Symias:...» (1446-1447, Pero Díaz de Toledo, Traducción del Libro llamado Fedrón, de Platón).

6. «E cada vno dellos es muy grande e muy malo e muy mortal para el cuerpo e para el alma» (1293, Anónimo, Castigos e documentos para bien vivir). ${ }^{36}$

7. «a mas baxa parte de la nuve, do la materia es mas terrenal. Estas son sus colores mas prinçipales» (1494, Fray Vicente de Burgos, Traducción de El Libro de Proprietatibus Rerum).

Tabla 7: Posibilidad de aparecer graduados

\begin{tabular}{|l|l|l|l|l|}
\hline ageno & carnicero & celestial & comunal & criminal \\
\hline divinal & divino & mortal & público & rústico \\
\hline seglar & terrenal & \multicolumn{4}{|l}{$24 \%$} \\
\hline
\end{tabular}

Por otro lado, está claro que muchos de los ejemplos aquí mencionados serían considerados agramaticales en la actualidad - muy mortal - pero eran perfectamente aceptables en la época que estamos analizando.

Tampoco podemos perder de vista que el genitivo en sí mismo está disponible para la comparación o la contraposición: esto es más de hombres que de mujeres - magis virorum quam mulierum est. De hecho, las situaciones de relación son comparables entre sí aunque no graduables, esto explica que, si bien ya en español antiguo son pocos los casos en los que estos adjetivos aparecen en superlativo, no parecen tener mucho problema para aparecer en estructuras de contraposición o de comparación. En este sentido, la situación no es muy diferente a la actual, aunque sí se da una mayor flexibilidad.

2.3.4. Relación con los nombres

Dentro de los adjetivos, estos son los más periféricos, los más parecidos a los nombres; ya he comentado que, de hecho, se usan para expresar relaciones que en latín se expresaban con nombres en genitivo. Por otra parte, en

${ }^{36}$ Obsérvese en este caso la coordinación con adjetivos valorativos. 
mi documentación, de los 50 adjetivos analizados, 33 de ellos pueden aparecer sin acompañar al sustantivo, funcionando como un auténtico sustantivo, que puede cumplir diferentes funciones sintácticas. Presento una mínima muestra:

1. «la trinidad de las personas \& las .ix. ordenes de angelicales divididas en .iii. hierarchias» (1494, Fray Vicente de Burgos, Traducción de El Libro de Proprietatibus Rerum).

2. «la que nos redemió; torne cosa angélica la que carnal nació, que nos tornen al cielo, ont Lucifer ...» (1228-1246, Gonzalo de Berceo, Del sacrificio de la misa). ${ }^{37}$

3. «quando la ciudat terrenal es semblant a la celestial, en la qual todos han vna volumtat» (1376-1396, Juan Fernández de Heredia, Libro de actoridades (Rams de flors)).

4. «mero misto inperio, asy en lo çevil commo en lo criminal, por syenpre jamás, sobre el dicho lugar» (1433, Anónimo, Escritura de reconocimiento $).{ }^{38}$

5. «Despues desto enuio por un estrellero que era muj sabio en aquella sciencia» (1270-1284, Alfonso X, Estoria de España, II).

6. «fue grand el combatimiento de combater los. vltramarinos. que firuien con ligereza. desseando uençer» (1270-1284, Alfonso X, Estoria de España, II).

7. «vosotros los mundanos que despendéis nuestra vida con affán» (1400-1500, VV.AA., Cancionero castellano del s. XV de la Biblioteca Estense).

8. «non catando en como era nuestro vasallo e nuestro natural e quantas merçedes ouo de los reyes» (1328, Anónimo, Respuesta de Alfonso XI al IV de Aragón a la embajada ....). ${ }^{39}$

9. «solamente pueda dar las órdenes todas salvo la obispal que se deve dar segund dicho es» (1325, Pedro de Cuéllar, Catecismo).

10. «Pues el sotil palaçiano quanto más e más privare por tal yerro» (1453, Marqués de Santillana, Doctrinal de privados).

${ }^{37}$ En este ejemplo realmente estamos ante la elipsis del nombre, al igual que en algunos de los ejemplos mostrados: cosa carnal, ciudad celestial, orden obispal.

${ }^{38} \mathrm{En}$ los casos en que lo precede al adjetivo ha habido discusión en torno al estatuto sintáctico de este. Sigo, en este caso a Alarcos (1994), cuando dice que $l o$ sustantiva al adjetivo como los demás artículos. Este autor añade: «Cuando se dice el negro o la nueva se hace una referencia anafórica a un sustantivo eludido, pero presente en la mente de los interlocutores (puede ser, por ejemplo, el libro o el traje o la casa o la canción). Al decir, en cambio, lo nuevo o lo negro, no hay posibilidad de imaginar un sustantivo explícito, porque se alude a un conjunto de referencias no asignable a ningún género, es decir, a la cualidad común designada por nuevo en un conjunto de objetos» (ib., 81). Por su parte, Salvador Gutiérrez Ordóñez (1997, 229 254) presenta, apoyándose en Iglesias (1986), una sólida argumentación a favor de la capacidad sustantivadora del artículo, que permite crear construcciones exocéntricas, resultado de la transposición sintáctica.

${ }^{39}$ Obsérvese cómo en este caso incluso encontramos un posesivo precediendo a natural, prueba evidente de que estamos ante un auténtico sustantivo. 
Tabla 8: Función como sustantivo

\begin{tabular}{|l|l|l|l|l|}
\hline ageno & angelical & añal & ballestero & candial \\
\hline carnal & carnicero & castellano & celestial & criminal \\
\hline cristiano & divinal & divino & elegíaco & estrellero \\
\hline francés & griego & marino & molar & morisco \\
\hline mortal & mundanal & mundano & natural & obispal \\
\hline palaçiano & público & romano & rústico & seglar \\
\hline serrano & spirital & toledano & & $66 \%$ \\
\hline
\end{tabular}

Por otra parte, son los únicos adjetivos que, hoy en día, pueden llevar una prefijación culta (pre-, post-, anti-, neo- paleo-, ante- ...). Estos son prefijos, como señala Demonte (1999), que, de hecho, acompañan a sustantivos normalmente: antidroga, premamá, postcomunismo, antipapa, muestra de la cercanía de los adjetivos relacionales con los sustantivos. El uso de estos prefijos, que en la actualidad sirve para diferenciar adjetivos relacionales y calificativos - que solo admiten prefijos intensificadores: rebonita, requetesimpático ... -, era, sin embargo, mínimo en la época medieval y, obviamente, por tanto, no es un parámetro válido para la diferenciación. En la búsqueda realizada de los prefijos pre-, post-, neo-, paleo- y anti- con los adjetivos analizados, no hemos documentado ningún ejemplo y es que estamos ante un procedimiento de creación de palabras que empieza a ser productivo en español en época más tardía que la sufijación. ${ }^{40}$

Llama la atención esta ausencia de prefijación en la antigüedad aunque se justifica, precisamente, por su carácter culto. Los únicos prefijos localizados con este tipo de adjetivos son ULTRA- y EXTRA- y ambos con una mínima frecuencia y compatibles también con adjetivos calificativos:

1. «por posedir Gallia. Et como Vualanir, rey de los extragodos, et Ardarico, rey de los gipidas» (1377-1399, Juan Fernández de Heredia, Traducción de Breviarium ab urbe condita, de Eutropio). ${ }^{41}$

2. «e testamentos e obligaciones e abtos judiçiales e extra judiçiales pasen ante estos escrivanos» (1495, Anónimo, Real Cédula de los señores Reyes Católicos).

3. «muytas gentes de otras partes que decendieron de ultramontanos, que era fuera de las Spannyas» (1376-1391, Juan Fernández de Heredia, Gran crónica de España, III).

Quiero llamar la atención sobre el prefijo ULTRA- cuando antecede al adjetivo marino ya que es el único caso en que este prefijo sería productivo; de todas formas, aquí hemos de hablar de lexicalización, en el sentido de que, aunque

${ }^{40}$ No ocurría lo mismo en latín, donde la prefijación es el proceso derivativo más productivo.

${ }^{41}$ Quizás sea una mala lectura de ostrogodos. 
su valor como prefijo sigue vivo, constituye un adjetivo y un sustantivo (ultramar) con una vinculación total entre las partes y un significado unitario.

1. «fue grand el combatimiento de combater los. vltramarinos. que firuien con ligereza. desseando uençer» (1270-1284, Alfonso X, Estoria de España, II).

2. «nuestros reynos y tierras, assi citra como vltra marinas, yr a las partes de Affrica, senyaladamente» (1489, Anónimo, Fernando otorga salvoconducto a favor de Juan de Pugeus). ${ }^{42}$

Esta ausencia generalizada de prefijos no resta valor a la hipótesis de su relación con los nombres sino que, simplemente, alude a un proceso de creación léxica más tardío; hay, así, otras realidades sintácticas que nos orientan hacia esta situación cuasinominal de estos adjetivos. Las veremos a continuación.

Los adjetivos relacionales no presentan antónimos, según autores como Schmidt (1972) o Bache (1978), entre otros, y, por tanto, no pueden formar parte de sistemas binarios y ser términos de correlaciones de polaridad. Así, frente a oposiciones como grande - pequeño, feo - guapo, bueno - malo ... los relacionales no entran en estas escalas ni presentan antónimos, ya que, por ejemplo, celestial no es lo contrario de terrenal sino que indica una relación diferente, no su negación. Por otra parte, como señalan Bosque (1993, 22) o Fábregas $(2005,146)$, cuando los adjetivos relacionales llevan un prefijo negativo no designan su antónimo sino la exclusión de la clase representada por el adjetivo relacional: gramatical/agramatical, legal/ilegal ...

En este sentido, se justifica la teoría de que estamos ante una categoría gramatical que compensa la desaparición del caso genitivo, el cual servía para marcar también diferentes relaciones, no para negar: VIRUM/VIRORUM - 'de hombres' no es lo contrario que MULIERUM - 'de mujeres', por ejemplo. Así, es otra buena muestra de la estrecha relación existente entre el nombre y este tipo de adjetivo. Los nombres, al igual que estos adjetivos muestran una complejidad de relaciones, que impide que se puedan oponer en correlaciones de polaridad; así casa no es lo contrario que apartamento sino otro tipo de vivienda y toledano no se opone a griego sino que expresa una relación diferente. De todas formas, y aunque la relación con los nombres no se pone en duda, en este punto tenemos que hacer unas matizaciones a lo que estos autores afirman. En los ejemplos de adjetivos de gentilicios (toledano, griego ...), en los de profesiones (carnicero, ballestero ...) o en los que indican religión (cristiano, morisco ...), entre otros, es evidente que no existe la posibilidad de antonimia pero hay otros casos en los que, aunque no podamos hablar de antonimias propiamente dichas, la situación no es tan evidente; en

\footnotetext{
${ }^{42}$ Obsérvese que en este último ejemplo el valor gramatical del prefijo es todavía evidente.
} 
este sentido, no podemos perder de vista la mentalidad medieval que organizaba el mundo en dicotomías: carnal vs. spirital; mundanal, umanal vs. divinal, terrenal vs. celestial etc.

1. «no te dé miedo el espanto, que si fue carnal el metal, las manos del oficial son del Spíritu» (1467-1482, Frey Íñigo de Mendoza, Coplas de Vita Christi).

Tomo, pues, este criterio con cierto recelo ya que al estudiar una etapa de una lengua no podemos dejar de tener en cuenta a los hablantes y su forma de organizar y nombrar el mundo en el que viven.

Por otro lado, la secuencia formada por un nombre y un adjetivo relacional es compacta por lo que en español actual no pueden intercalarse entre ellos adjetivos calificativos ni modales o circunstanciales. Solo pueden intercalarse adverbios focalizadores, con ciertas restricciones; así, de los tres tipos de adverbios focalizadores que distingue Kovacci (1999): exclusivos (únicamente, exclusivamente), particularizadores (particularmente, especialmente) e identificativos (exactamente, justamente), solo los primeros pueden intercalarse, y no siempre, entre el nombre y el adjetivo que lo modifica: actuación exclusivamente policial pero *estilo exactamente arquitectónico. Una relación tan estrecha entre nombre y adjetivo no se daba en español antiguo, y por eso encontramos casos en los que nombre y adjetivo no están en situación de adyacencia, ya que, incluso, puede aparecer un verbo interpolado. Es la misma situación que se daba en latín, donde, aunque normalmente el nombre en genitivo se colocaba tras el nombre al que clasificaba, podían aparecer elementos intercalados. Obsérvese, en este sentido, que casi todos los ejemplos que presentamos a continuación podrían ser sustituidos por «de + sustantivo», construcción heredera del genitivo latino (de otro, del cielo, de Dios, de Francia, del campo, del hombre, del mundo, de Toledo).

Además quiero llamar especialmente la atención sobre la importante presencia de adjetivos calificativos intercalados en los ejemplos analizados: mundo alto celestial, rropa corta francesa, cuerpo verdadero humano, albornoz prieto morisco, medida vieja toledana... estructuras hoy inexistentes ya que preferimos: ropa francesa corta o cuerpo humano verdadero, donde el calificativo modifica al bloque formado por el sustantivo + el adjetivo relacional. De hecho, según señala Santos Río (2000, 288), la única ordenación posible en español actual es: «... /Calificativos No Restrictivos / Nombre / Relacionales Clasificativos / Argumentales / Calificativos Restrictivos... y la estructura... [[CNRestr [[N] RCl] Arg] CRestr...». Esta situación me lleva a ratificarme en la hipótesis de que en español antiguo existía una mayor libertad posicional del adjetivo porque, salvo en el caso de las fórmulas fijadas o fraseológicas, el adjetivo relacional no formaba todavía un bloque compacto con el sustantivo modificado. Su carácter cuasinominal tiene un papel decisivo en esta realidad. 
1. «Et otroquesi, tod aquel que en casa estidiere agena, et por el mandamiento del sennor dela casa ...» (1218-1250, Fuero de Zorita de los Canes).

2. «por cobrar la tu fuerça / lobo eres carnicero» (1330-1344, LBA, 291d). ${ }^{43}$

3. «\& de corruption uertudes \& obras del mundo alto celestial que es apoderado dellas» (1256, Alfonso X, Picatrix, Vat. Reg.).

4. «seysmas de çebti carmesy, para vna rropa corta francesa, que costo a 1.300 la vara, 3.683 mrs.» (1477-1491, Anónimo, Cuentas de Gonzalo de Baeza, tesorero de Isabel la Católica).

5. «caualgadores o apellidores fazienda ouieren campal, e ante que la senna torne del alcançe» (1300, Fuero de Alarcón).

6. «Por esto la ley musaica, e más verdaderamente divina, dio aquellos diez mandamientos donde nasçen ...» (1427-1428, Enrique de Villena, Traducción y glosas de la Eneida. Libros I-III). ${ }^{44}$

7. «e que el cuerpo de Cristo fuesse cuerpo verdadero humano de carne \& huesso et non fuesse cuerpo fantast ...» (1437, El Tostado (Alonso Fernández de Madrigal): Libro de las paradojas).

8. «doradas las guarniciones; - un albornoz prieto morisco más cuatro hazes de almadraques reales» (1441, Anónimo, Inventario de los bienes de Diego López de Ayala).

9. «los deleites que aún quedan en la maginaçión mundanos, maguer que sin viçio. E lánçalos en la mar» (1427-1428, Enrique de Villena, Traducción y glosas de la Eneida. Libros I-III). ${ }^{45}$

10. «de agosto de cada año por la dicha medida vieja toledana que se solía usar antes de la mi ordenança» (1457, Anónimo, Carta de confirmación y privilegio de Enrique IV).

Se observa, pues, que estos adjetivos están funcionando de la misma forma en que lo haría un nombre en genitivo.

\subsubsection{Otros rasgos sintácticos}

Termino el apartado referido a la sintaxis comentando algunas otras características de estos adjetivos.

Hemos visto algunas diferencias con el español contemporáneo pero lo que sí es posible tanto en español antiguo como en español actual es que en un sintagma concurran varios adjetivos relaciones o complementos del nombre:

1. «angelical, San Miguel, y del glorioso mensajero celestial arcángel San Gabriel» (1491-1516, Alonso de Santa Cruz, Crónica de los Reyes Católicos).

2. «De sentencia definitiva criminal dose marauedis, que es el catorseno capitulo» (1458, Anónimo, Ordenanzas de Ávila). ${ }^{46}$

${ }^{43}$ En este caso es la rima la que determina el orden.

${ }^{44}$ En este caso el adverbio sería de carácter identificativo y, por tanto, según Kovacci, no podría aparecer intercalado.

${ }^{45}$ Esta distorsión del orden lógico se debe tanto al esfuerzo latinizante como a las necesidades de la rima.

${ }^{46}$ Aquí lo que extraña es el orden de los adjetivos. 
3. «Estos cuatro dalfines tiran el divinal carro neptúnico allanando las undaçiones» (1427-1428, Enrique de Villena, Traducción y glosas de la Eneida. Libros I-III).

4. «murieron tres mil hombres. Y que la jente de armas francesa escapó la mayor parte desbaratada» (1491-1516, Alonso de Santa Cruz, Crónica de los Reyes Católicos). ${ }^{47}$

5. «Lucrecia. segund se dize fue vna dueña noble romana nieta de bruto: \& muy fermosa» (1490, Alonso de Palencia, Universal vocabulario en latín y en romance).

6. «dellas e de su monesterio dos cafiçes de sal toledanos, Et agora la dicha rreyna doña maría ...» (1340, Anónimo. Merced Alfonso XI bernardas $).{ }^{48}$

En cuanto a sus posibilidades de coordinación, se supone que los adjetivos relacionales no pueden coordinarse con los calificativos. Es evidente que la coordinación suele exigir elementos equivalentes, por eso solo pueden coordinarse entre ellos y con restricciones. Dice Violeta Demonte $(1999,171)$ que los adjetivos relacionales solo pueden coordinarse cuando tienen exactamente la misma función semántica y cuando la restricción que uno impone no incluye o es incluida por la otra sino que ambas son complementarias; así, no serían posibles construcciones tales como ${ }^{*}$ cartel publicitario y luminoso $^{49}$ o - y este ejemplo ya es mío - ? *soy onubense y andaluza.

Es esta una regla, sin embargo, que quizás no sea tan tajante como algunos proponen, ya que podemos decir que alguien es rubio y universitario; no es lo habitual pero no creo que los hablantes rechacen, realmente, estructuras como estas, en determinados contextos, sobre todo en lengua oral conversacional. Pues bien, esta flexibilidad era mayor en el español antiguo y en mi documentación cuento con varios casos de coordinación entre relacionales y valorativos. Se podría matizar, eso sí, que en algunos de los casos de coordinación que se presentan se puede observar cierto desplazamiento semántico del adjetivo hacia lo valorativo y así, por ejemplo, carnal 'de la carne', al tener connotaciones negativas, puede con tales connotaciones, coordinarse con adjetivos valorativos negativos como falsa o mesquina.

1. «Alexandre, guarda la tu noble anima alta et angelical que acomendada es a tu» (1376-1396, Juan Fernández de Heredia, De secreto secretorum).

2. «que vido la correpçion del padre ser vil \& falsa \& carnal \& ynfinitosa \& ynReuerente a dios» (1293, Anónimo, Castigos).

3. «y deuoto almirante: dixo le / y conel rostro tan celestial y fermoso: porque me inuocaste con tanta fe» (1499, Gonzalo García de Santa María, Traducción de la Corónica de Aragón).

${ }^{47}$ En este caso el adjetivo modifica a «gente de armas». Lo normal, cuando hay más de un modificador del nombre, es que el adjetivo situado más a la derecha sea el que abarque al nombre y al primer adjetivo o complemento preposicional.

48 Junto a una fórmula como esta encontramos la forma sin intercalación en el mismo texto: «bernaldo de guadalfaiara con estos dos cafiçes toledanos de sal que án de aver commo sobredicho és» (1340, Anónimo, Merced Alfonso XI bernardas).

${ }^{49}$ Lo correcto sería en este caso la adyacencia: cartel publicitario luminoso. 
4. «solo por seguridat de la vida. Los quales como umano y virtuoso señor vuestra señoria resçibio» (1475, Pero Guillén de Segovia, La gaya ciencia). (Es el único caso de valorativo que he encontrado.)

5. «Item un aniello de oro, grande, obispal, con camafeo et con piedras buenas» (1275, Anónimo, Inventario de bienes de la catedral ...).

6. «lo firio $*$ y la ferida era grande e mortal, assy que el cauallero entendio en su muerte» (1348-1379, Anónimo, Gran crónica de Alfonso $X I$ ).

7. «seys años despues. fue crudamente: y de vna mortal y terrible cantera muerto. ca teniendo çercada» (1499, Gonzalo García de Santa María, Traducción de la Corónica de Aragón).

Antes de referirme a las características semánticas de los adjetivos relacionales, algunas de las cuales he ido avanzando en las páginas anteriores, quiero hacer una breve recapitulación de lo dicho hasta ahora.

- El 72\% de los adjetivos analizados pueden anteponerse a un nombre que funciona como complemento, proporción que disminuye cuando el nombre es núcleo de un sujeto hasta el $36 \%$, cifra mucho menor pero que sigue dando cuenta de la posibilidad de anteposición del adjetivo frente a la situación del español actual.

- El 46\% de los adjetivos estudiados aparece en alguna ocasión funcionando como predicado.

- Hay un 24\% de adjetivos que en alguna ocasión pueden aparecer graduados, sin que se perciba claramente un significado valorativo. Aunque no hablamos de una proporción muy alta, sí lo es comparada con la de la lengua moderna.

- Dado que son adjetivos que, como he indicado, funcionan igual que lo hacían los nombres en genitivo, no es de extrañar que, igual que hoy, puedan funcionar en ocasiones como sustantivos; así lo hace en alguna ocasión el $66 \%$ de los adjetivos analizados.

- Son los únicos adjetivos que, hoy en día, pueden llevar una prefijación culta (pre-, post-, anti-, neo-, paleo-, ante-...), al igual que los nombres. En español antiguo, salvo con extra- o ultra- se da una ausencia generalizada de estos prefijos; este hecho, sin embargo, no resta valor a la hipótesis de su relación con los nombres sino que, simplemente, alude a un proceso de creación léxica más tardío.

- Estos adjetivos, dada su similitud con los nombres, no presentan antónimos propiamente dichos pero no podemos perder de vista la mentalidad medieval que organizaba el mundo en dicotomías: carnal vs. spirital; mundanal, umanal vs. divinal, terrenal vs. celestial etc.

- A diferencia del español actual pueden aparecer elementos intercalados entre el nombre y el adjetivo relacional que lo acompaña. Si tenemos en cuenta que estamos analizando una categoría en evolución, no ha de extrañarnos esta situación ya que no estamos aún ante estructuras compactas.

- Hemos visto algunas diferencias con el español contemporáneo pero lo que sí es posible tanto en español antiguo como en español actual es que 
en un sintagma concurran varios adjetivos relaciones o complementos del nombre.

- No es, sin embargo, la misma situación en lo que respecta a la coordinación con adjetivos valorativos, combinación imposible hoy para algunos autores - yo driría que costosa, no imposible - pero relativamente habitual en español antiguo.

Estos adjetivos surgen, pues, en gran medida, como compensación a la desaparición del genitivo y, en este sentido, presentan en ocasiones características sintácticas muy cercanas a las de los nombres, lo que les permite actuar con una mayor libertad en la frase, tanto en lo que se refiere a su libertad posicional como a su facilidad para funcionar como atributos, admitir elementos intercalados o aparecer como auténticos sustantivos. Por otra parte, parece evidente, a la vista de los datos mostrados, que las diferencias que hoy en día se establecen entre adjetivos relacionales y calificativos no eran tan tajantes en español antiguo. Estamos aún ante una categoría en formación, lo que permite que se den todavía en esta época importantes vacilaciones que van desapareciendo a lo largo de los siglos, como se ha podido comprobar con la comparación con el español clásico y los datos que conocemos del español actual. En todo caso, lo que parece más significativo es que la sintaxis de estos adjetivos se orienta desde una situación con mínimas restricciones a una situación con unas restricciones mucho mayores:

[- restricciones] $\rightarrow$ [+ restricciones $].$

\subsection{Breves notas sobre la semántica de estos adjetivos}

Me detendré a continuación muy brevemente en algunos aspectos semánticos. Lo primero que quiero destacar es la menor polisemia de estos adjetivos en español antiguo que en español actual; se trata de una situación lógica ya que las palabras se van cargando de nuevos significados a lo largo de su andadura en el tiempo pero hay un punto que me parece especialmente significativo: los valores que van adquiriendo los conducen, en ocasiones, a pasar de relacionales a valorativos. Así, algunos de estos adjetivos que hoy en día se usan habitualmente como calificativos, en español medieval solo tienen el valor posible de relacional o si han adquirido este nuevo valor, es solo en época muy tardía; de hecho, en la documentación de finales del siglo XVII que he manejado todavía muchos de ellos se usan solo como relacionales.

Sobre la adquisición de nuevos valores reflexionaban ya Cabré et al. (2000, 204): «Además en algunos casos en los que el adjetivo se lexicaliza, es posible encontrar dos significados: una acepción semánticamente transparente, uso relacional propiamente dicho (dantesco 'relativo a Dante), y otra no predictible sin conocimientos enciclopédicos (dantesco 'terrorífico')», aunque estas autoras no tienen en cuenta la diacronía, sino solo las diversas posibilidades que podemos encontrar en la sincronía. 
Hoy día, alguien o algo angelical es alguien o algo ‘adorable, dulce, bello’ y no solo 'de los ángeles', que es el valor básico de este adjetivo en los ejemplos analizados hasta el siglo XV, cuando ya se percibe este nuevo valor en algunos casos: clavellina angelical, semblante angelical.

En el XVII, se observa que en el caso de angelical y angélico conviven el valor etimológico y el nuevo significado calificativo:

1. «que bajó el ángel; pureza angelical en lo blanco del hábito, mostrando que no ...» (1609, San Juan Bautista de la Concepción, Apuntes sueltos en torno a la reforma ...).

2. «luego es compuesta de lo mismo. Que su alma es angélica nadie lo duda, siendo de naturaleza intelectual» (1644, Antonio Enríquez Gómez, El siglo pitagórico y Vida de don Gregorio Guadaña).

3. «porque aquí los ojos ven hermosura angelical. Laureta (Aparte.) Mirad si la quiere mal» (1610, Luis de Góngora y Argote, Las firmezas de Isabela).

La secuencia en este sentido parece clara: 'de los ángeles' (relacional argumental) > 'propio de los ángeles' (calificativo) > 'bueno, bello' (valorativo).

Del mismo modo, en español medieval humano, mundanal o mundano, terrenal se oponen, en cierta medida, a otros adjetivos como divinal, divino, celestial o spirital; los primeros tienen que ver con lo relativo al hombre y a la tierra y los segundos con lo relacionado con Dios, el cielo y el espíritu; e ynfernal solo se refiere al infierno. Únicamente en algún ejemplo aislado tardío, que ya hemos mencionado, pueden verse valores similares a los que estos adjetivos pueden tener en la actualidad.

Así, aunque la mayor parte de los usos de celestial todavía en la segunda mitad del siglo XVII son claramente relacionales, se observa una evolución hacia el significado valorativo gracias a la comparación o a la metáfora:

1. «El calor de las Musas me enciende el entendimiento, ¿por dónde queréis Diosas que vaya? Y en la verdad todos tuvieron por tan estraño el espíritu poético, que no supieron cómo llamarle sino celestial» (1651, Jerónimo de Cáncer, Obras varias).

Lo mismo ocurre con infernal que, en ocasiones, es claramente valorativo:

1. «assí despreciado y vencido dellos, procuró con infernal astucia echarlos de la tierra» (1657, Bernardo de Torres, Crónica Agustina, Perú).

Mortal 'relativo a la muerte' rara vez posee el valor de 'terrible' con el que, a veces, lo usamos en la actualidad y que ya aparece en el siglo XVII con cierta frecuencia:

1. «Y ansí arremete el turco Con gran saña y mortal ira» (1693, Anónimo, Romances, en Silva de varios romances).

2. «... de sí esté; que sin hablar, sin oír ni ver, con mortal despecho, despedazándose el pecho» (1660, Pedro Calderón de la Barca, El diablo mudo). 
Criminal 'del crimen', por su parte, no aparece nunca con el valor de 'malvado'. Solo en el siguiente ejemplo del español clásico, en el que hay una gradación, podría considerarse que el valor no es tanto 'del crimen, relativo al crimen' como 'malo, dañino', por lo cual podría decirse que ya es valorativo:

1. «Dos tiempos abraça la primera proposición: el de la paz i el de la guerra; i aunque con la diferencia de más o menos criminal, en ambos la tengo por certíssima» (1655, Antonio López de Vega, Paradojas racionales).

Hoy se pueden usar, en ocasiones, los gentilicios como indicadores de cualidad y no como relacionales propiamente dichos; así, podemos decir: yo soy muy española. En la época que nos ocupa no hay ningún ejemplo que nos oriente en esta dirección y no hay ejemplos del tipo ser muy castellano, muy griego o muy extraño ('extranjero'). Lo mismo ocurre con los adjetivos que indican religión: no hay casos de alguien que sea muy arriano o muy cristiano. El primer ejemplo de este uso lo encontramos a finales del siglo XVII:

1. «A D. Diego de Portugal se dió el gobierno de Ceuta, eleccion de gusto y aprobacion de todos, por ser este caballero muy gran soldado, muy desinteresado y muy cristiano, y estar sin el premio de sus servicios» (1677-1678, Juan Antonio de Valencia, Diario de noticias de 1677 a 1678).

Además es necesario añadir que la dirección de esta tendencia es siempre en un único sentido: relacional > valorativo. ${ }^{50}$ Así, lo que antes indicaba propiedades objetivas y definitorias (carnal - 'de la carne', 'relativo a la carne') pasa a indicar algo subjetivo (carnal - 'lascivo, sensual, lujurioso'). ${ }^{51}$ Se trata de un cambio unidireccional e irreversible, ya que nunca se da en sentido contrario. ${ }^{52}$ Esta dirección viene, en general, determinada por la pérdida de tivo.

${ }^{50}$ Posiblemente, a través de un proceso gradual: relacional > cualitativo > valora-

${ }^{51}$ En el caso del adjetivo carnal estamos ante un cambio muy temprano en nuestra lengua y ambas acepciones son recogidas por Covarrubias (1611) como usuales: «Lo que pertenece a la carne; 2 y al hombre que es muy dado a la sensualidad y vicio de la carne, le llamamos carnal». En cualquier caso, conociendo las ideas cristianas que en la época medieval oponen espiritual a carnal y que relacionan, por tanto, la carne con el hombre y el pecado, no puede extrañar ese paso a 'sensual, lascivo, lujurioso', atestiguado en época temprana. Para entender, pues, los cambios que en los diferentes niveles ha ido sufriendo este adjetivo hay que enlazar, pues, necesariamente explicaciones externas con explicaciones lingüísticas internas. También Bosque (2004, 445) recoge para el español actual la doble significación pero, en este caso, las posibilidades combinatorias del adjetivo con valor relacional aparecen muy restringidas. De hecho, la nómina de sustantivos con los que puede combinarse se reduce unos pocos nombres de parentesco: tío, pariente, sobrino y primo.

${ }^{52}$ Sí es verdad, sin embargo, que en casos como arroz blanco, piel roja o partido verde los adjetivos cualitativos parecen haberse convertido en adjetivos relacionales que sirven para clasificar pero en estos casos es la construcción en su globalidad la que aporta el significado y es 'el arroz blanco', como construcción, el que se opone, por ejemplo a «paella». 
composicionalidad semántica. En origen estos adjetivos eran transparentes morfológicamente y su significado se resuelve por el significado de las partes que los componen, así, rústico se compone de dos semas que nos permiten entender que se refiere a algo relacionado con el campo o perteneciente al campo, pero, poco a poco, en determinados casos, la transparencia morfológica va desapareciendo y el uso contextual da a unidades complejas un significado global, por lo que el hablante no identifica ageno como procedente de ALIENus 'de otro' o divino como 'de Dios'. Esto es lo que ocurre con los adjetivos valorativos, en los que el significado global no es deducible de las partes; y es así como se explica el paso de relacional a valorativo y el que no se conozcan situaciones contextuales en las que sea un adjetivo valorativo el que se convierta en relacional.

Al mismo tiempo la posibilidad de este cambio así como su unidireccionalidad es explicada con precisión y acierto por Almela (2000, 297):

«[...] con independencia de los sentidos, contextuales, que el hablante pueda asignarle a un determinado adjetivo relacional, éste es portador de tres tipos de interpretaciones (identificadora, subclasificadora y analógica), como propone Tamba-Mecz (1980: 131-132). Del sintagma sonido musical puedo hacer: (1) una interpretación identificadora, esto es, un sonido de la música, propia de de esta actividad; (2) una interpretación subclasificadora, o sea, un sonido opuesto a cualquier otra procedencia o actividad que no sea la música; (3) una interpretación analógica, es decir, un sonido comparable, similar a otro que produce un instrumento musical. Esta triple posibilidad origina la polisemia de los adjetivos relacionales. Cuando se dice camisa europea, se puede entender que es una camisa típica de Europa, o que ha sido fabricada o comercializada en Europa, o que es de un estilo semejante al estilo de los objetos que se usan en Europa ... El adjetivo calificativo carece de una virtualidad que lo acerque al relacional; por eso tiene en sí mismo menos posibilidades de ejercer la ‘unción〉 habitual del adjetivo relacional».

Los nuevos valores de estas palabras, pues, no serán ya tanto para clasificar los objetos por ellas designados sino para expresar sus cualidades, una vez que la pérdida de composicionalidad semántica ha desembocado, en algunos casos, en un significado unitario y global, y no ya en el resultante de la suma de los significados de las partes que componen estos adjetivos, lo que facilita la interpretación analógica.

Nos encontramos, pues, ante un cambio semántico con importantes repercusiones en la sintaxis ya que adjetivos relacionales en origen pasan a convertirse en valorativos y adoptan, por tanto, su comportamiento sintáctico. En este sentido, coincido con Almela (2000, 303) en que habría que hablar de «refuncionalización» de estos adjetivos más que de «recategorización».

En este caso parece que el cambio semántico es el que trae consigo los cambios sintácticos, lo que viene a confirmar la teoría de la gramaticalización desde el punto de vista de la Gramática General: los cambios sintácticos son consecuencia de los cambios semánticos. En muchos de los adjetivos analiza- 
dos podemos ver cómo las características sintácticas de un adjetivo valorativo (posibilidad de anteposición, coordinación con valorativos, aparición como predicado ...) se observan desde muy pronto en adjetivos que al principio son claramente relacionales; y es que la diferencia de comportamiento sintáctico no está aún establecida claramente.

Por otro lado, conocemos cuándo determinados adjetivos, tras algunos ejemplos en los que su significado puede resultar ambiguo, empiezan a ser claramente valorativos porque hay ejemplos clásicos evidentes, pero llama la atención que la sintaxis sea siempre muy flexible y que no se observen cambios sintácticos cuando un adjetivo adquiere un nuevo valor. Los iniciales cambios semánticos no repercuten, pues, en la sintaxis. Sin embargo, en aquellos casos en los que el cambio semántico no se produce, estos adjetivos acaban por fijar su sintaxis y es lo que observamos en el español actual, donde las restricciones sintácticas de los adjetivos relacionales son mucho mayores.

Tabla 9: Adjetivos relacionales que pueden tener una lectura como valorativos

\begin{tabular}{|l|l|l|}
\hline ageno & angelical & carnal \\
\hline carnicero & celestial & criminal \\
\hline cristiano & divino & humano \\
\hline mundanal & mundano & natural \\
\hline rústico & serrano & spirital \\
\hline terrenal & ynfernal & $34 \%$ \\
\hline
\end{tabular}

La semántica parece ser relevante para explicar el funcionamiento sintáctico de estos adjetivos; de hecho, según algunas corrientes lingüísticas, como ya he avanzado, la estructura léxica incide en la sintaxis y nos permite conocer los procesos sintácticos e incluso predecirlos. Personalmente, no sé si podemos llegar tan lejos pero lo que sí parece evidente es que la relación existe. En el caso de los adjetivos que he analizado, está claro que los adjetivos relacionales pueden, en ocasiones, ser ambiguos. Pero si tenemos en cuenta la teoría de Pustejovsky (1995) sobre la estructura de Qualia: «podemos concluir [...] que la interpretación que se haga de ciertas construcciones no depende de la sintaxis de los adjetivos relacionales, esto es, de su posición respecto del nombre, ni siquiera del significado del nombre del que provienen, sino de la estructura semántica del nombre al que acompañan» (Abad 2004, 54). En este trabajo he analizado adjetivos muy diversos pero, como he avanzado, la polisemia es mínima y prácticamente no hay casos de ambigüedad; en este sentido, parece que en las primeras épocas del idioma los adjetivos mantienen cierta estabilidad en la selección de roles. Poco a poco, sin embargo, estos adjetivos han desarrollado más posibilidades semánticas, lo que permite un abanico más amplio en la selección de qualia. Ahora bien, aunque 
esta teoría pueda explicar algunos cambios en sincronía, una visión diacrónica nos permite explicar la naturaleza de los cambios desde una perspectiva más amplia.

\section{Conclusiones}

Para terminar, quiero hacer referencia a algunos de los puntos más importantes que se han abordado en esta investigación:

1. En primer lugar, llama la atención, cuando nos enfrentamos al estudio de los adjetivos relacionales, su escasa presencia en los inicios del idioma, presencia que va, poco a poco, acrecentándose con el paso de los años. En la época analizada, se observa, de hecho, un importante crecimiento en su número y en su frecuencia de uso sobre todo en el siglo XV, cuando no solo se crean nuevos adjetivos sino que se introducen también por vía culta adjetivos latinos que, hasta el momento, no se habían incorporado a nuestro idioma. Hemos de tener en cuenta que estamos tratando un tipo particular de adjetivos, que se forma a partir de una base nominal y se trata este de un procedimiento complejo que tiene una evolución lenta y gradual desde el latín hasta la actualidad.

2. En latín existían ya muchos de estos adjetivos pero tenemos que recordar también que los sustantivos en genitivo cumplían la misma función y eso hace que la presencia de estos adjetivos fuera menor. La caída de los casos, por tanto, va a ser un factor determinante en el incremento de este tipo de adjetivos en español.

3. Por otra parte, morfológicamente, se ha podido observar que se sigue una línea coherente en el sentido de que hay una tendencia a crear adjetivos con unos sufijos determinados a lo largo de toda la historia, entre los que -AL va a ser el predominante desde el principio. Fruto, sin embargo, de la relativa indefinición de este tipo de adjetivos en la época medieval es la posibilidad de nominalizarse formalmente (carnalidad, extranyedad), que se va perdiendo ya en la época clásica y que va quedando restringida, poco a poco, solo a los adjetivos calificativos. Por otra parte, la pérdida de transparencia morfológica y fonética va a tener, como hemos observado, repercusiones semánticas y sintácticas.

4. Estos adjetivos presentan, asimismo, un menor grado de fijación a nivel sintáctico que en el español actual; esta menor fijación o menor restricción sintáctica la advertimos en distintas situaciones:

a) en primer lugar, mientras que en español actual estos adjetivos han especializado su uso colocándose detrás del nombre al que modifican, en la época que analizamos son muchos los casos en los que el adjetivo admite su colocación antepuesta; debida, en muchos casos a los esfuerzos latinizantes de la época - o al menos, a los esfuerzos latinizantes de la lengua literaria de la época -; 
b) por otra parte, estos adjetivos clasificadores no admiten en la actualidad la intercalación de elementos, a no ser una serie muy restringida de focalizadores, pero en español antiguo, con frecuencia, podían intercalarse elementos muy variados, muestra de que la relación sustantivo + adjetivo no se consideraba aún como un bloque compacto;

c) no podemos olvidarnos tampoco de que estamos ante adjetivos que provienen de nombres formalmente pero también funcionalmente ya que surgen como compensación a la caída de los casos, en concreto, a la desaparición del genitivo y por esa razón presentan un comportamiento, desde antiguo, similar a los nombres;

d) también aparecían funcionando frecuentemente como atributos, posición que, salvo los casos que se han comentado en el trabajo, parece estar destinada hoy en día únicamente a los adjetivos calificativos (cualitativos y valorativos);

e) al mismo tiempo, en la actualidad, no es posible la gradación de estos adjetivos pero en español antiguo podían aparecer con perífrasis de superlativo, aunque, eso sí, con cierto desplazamiento en ocasiones hacia los valorativos;

f) además, en ocasiones, podían coordinarse con adjetivos valorativos.

De los últimos puntos mencionados se deduce que estamos, en cierta medida frente a una categoría cuyo comportamiento sintáctico está en proceso de gramaticalización y que en español antiguo presenta muchas menos restricciones que en el español actual. Por tanto, algunos de los criterios empleados para la identificación de este tipo de adjetivo son solo relativamente válidos en español antiguo.

5. A nivel semántico, por otra parte, se ha observado una tendencia a evolucionar de relacional a valorativo a lo largo de la historia de nuestra lengua, pues muchos de los adjetivos que hoy presentan una doble lectura relacional-valorativa (celestial, mundano, divino ...) solo admiten la relacional en la antigüedad. No hemos visto ningún caso en sentido contrario, ya que se trata de un cambio unidireccional e irreversible provocado por la pérdida de composicionalidad semántica, que traerá como consecuencia una carga de significados valorativos en algunos adjetivos pero que no actúa en sentido contrario, convirtiendo valorativos en clasificadores.

Se observa, pues, cómo estos adjetivos se dirigen hacia una restricción en sus posibilidades sintácticas mientras que en lo que tiene que ver con la semántica se da la creación de nuevos valores, que nos llevan hacia otro tipo de adjetivos, que ya no presentarán las restricciones sintácticas de los relacionales puesto que adquieren otra nueva lectura valorativa, inexistente en el español antiguo y otro comportamiento sintáctico. Así, los adjetivos que he analizado en este trabajo han ido sufriendo una serie de evoluciones en todos 
los niveles hasta llegar al español actual y es esta evolución la que espero haya podido describir y explicar en estas páginas.

He explicitado, pues, a lo largo de este trabajo un proceso de cambio lingüístico que afecta a la categoría del adjetivo. He observado cómo el adjetivo relacional parece estar en una posición periférica dentro de la categoría del adjetivo pues algunos aspectos de su sintaxis lo acercan más al nombre que al propio adjetivo calificativo y he presentado también cómo se ha dado un proceso sintáctico de gramaticalización del que escapan los que adquieren nuevos valores calificativos no relacionales.

Partiendo de la hipótesis de que el adjetivo relacional se comporta en español antiguo en cierta medida como un nombre, sustituyendo a un genitivo, he mostrado que el proceso de cambio ha seguido la siguiente dirección: desde una situación en la que el adjetivo posee un único valor de relación, similar al genitivo - muchas restricciones semánticas, pues - y no presenta casi restricciones sintácticas, llegamos a la situación contraria: máximas restricciones sintácticas y mínimas restricciones semánticas, que permiten, en ocasiones, su paso a valorativos. Es posible que esa ampliación de valores semánticos observada en algunos de los adjetivos analizados - refuncionalización -, que no tiene lugar al menos hasta la época clásica, sea la que desencadene unas restricciones sintácticas que nos permiten marcar una línea divisoria clara y diferenciar hoy dos tipos de adjetivos: los relaciones y los calificativos con un comportamiento sintáctico claramente diferenciado. En este sentido, creo que la visión diacrónica que he presentado a lo largo de este estudio se muestra como una perspectiva innovadora y absolutamente necesaria para poder entender el funcionamiento de estos adjetivos y para comprender por qué los criterios empleados para su identificación pueden plantear excepciones, perfectamente asumibles desde esta nueva perspectiva.

\section{Referencias bibliográficas}

Abad Pastor, Raquel, Adjetivos relacionales en la interficie léxico-sintáctica, Trabajo de investigación, Madrid, Universidad Autónoma de Madrid, 2004.

Alarcos Llorach, Emilio, Estudios de gramática funcional del español, Madrid, Gredos, 1972, § 14 .

Alarcos Llorach, Emilio, El adjetivo, in: id., Gramática de la lengua española, Madrid, Espasa Calpe, 1994, 78-87.

Alcina Franch, Juan/Blecua, José Manuel, El nombre, in: iid., Gramática española, Barcelona, Ariel, 1975, 495-586.

Almela Pérez, Ramón, El orden AS/SA: la solución está en el conflicto, in: Wotjak 2000, 293-309.

Bache, Carl, The Order of Premodifying Adjectives in Present-day English, Odense, Odense University Press, 1978.

Bartoš, Lubomir, El llamado adjetivo relacional y su función en las unidades denominativas, in: Wiaczesław Nowikow (ed.), Lingüística española. Aspectos sincrónico y diacrónico, Wrocław, Wydawnictwo Uniwersytetu Wrocławskiego, 1995, $11-115$.

Bassols de Climent, Mariano, Sintaxis latina, Madrid, CSIC, 1971. 
Bosque, Ignacio, Las categorias gramaticales, Madrid, Síntesis, 1990.

Bosque, Ignacio, Sobre las diferencias entre los adjetivos relacionales y los calificativos, Revista Argentina de Lingüística 9 (1993), 9-48.

Bosque, Ignacio, Objetos que esconden acciones. Una reflexión sobre la sincategorematicidad, in: Teresa Cabré/Cristina Gelpi (edd.), Cicle de confèrencies 97-98: lèxic, corpus i diccionaris, Barcelona, Instituto de Lingüística Aplicada, 1997, 15-31.

Bosque, Ignacio, El sintagma adjetival. Modificadores y complementos del adjetivo. Adjetivo y participio, in: id./Demonte 1999, 217-310.

Bosque, Ignacio, Redes: diccionario combinatorio del español contemporáneo. Las palabras en su contexto, Madrid, SM, 2004.

Bosque, Ignacio/Demonte, Violeta (edd.), Gramática descriptiva de la lengua espanola, Madrid, Espasa Calpe, 1999.

Cabré, María Teresa, et al., Nombre propio y formación de palabras, in: Wotjak 2000, 191-206.

Demonte, Violeta, El adjetivo: clases y usos. La posición del adjetivo en el sintagma nominal, in: Bosque/ead. 1999, 129-215.

Demonte, Violeta, Configuración e interpretación de los adjetivos del español: un enfoque minimista, in: Wotjak 2000, 261-273.

Ernout, Alfred/Thomas, François, Syntaxe latine, Paris, Klincksieck, ${ }^{2} 1953$.

Fábregas, Antonio, La definición de la categoría gramatical en una morfología orientada sintácticamente: nombres y adjetivos, Tesis doctoral, Universidad Autónoma de Madrid, Instituto Universitario de Investigación Ortega y Gasset, 2005.

Fernández Ramírez, Salvador, Gramática española, vol. 3.1: El nombre (vol. preparado por José Polo), Madrid, Arco/Libros, 1986.

García González, Javier, Contribución al estudio de la sintaxis histórica del adjetivo en español, Tesis doctoral, Madrid, Editorial de la Universidad Complutense, 1990.

García González, Javier, La colocación del adjetivo atributivo en el español medieval, un problema metodológico e histórico, in: Ramón Lorenzo Vázquez (ed.), Actas do XIX Congreso Internacional de Lingüística e Filoloxía Románicas, vol. 5, La Coruña, Fundación «Pedro Barrié de la Maza, Conde de Fenosa», 1992, 819-827.

Gutiérrez Ordóñez, Salvador, Principios de sintaxis funcional, Madrid, Arco/Libros, 1997.

Hernanz Carbó, María Lluïsa/Brucart, José M., La sintaxis, vol. 1: Principios teóricos. La oración simple, Barcelona, Crítica, 1987.

Iglesias Bango, Manuel, El artículo en español: aportaciones a un viejo debate, Contextos 7 (1986), 115-127.

Kovacci, Ofelia, El adverbio, in: Bosque/Demonte 1999, 705-786.

Lapesa, Rafael, La colocación del adjetivo atributivo en español, in: Homenaje a la memoria de D. Antonio Rodríguez Moñino, Madrid, Castalia, 1975, 343-359; recogido también in: id., Estudios de morfosintaxis histórica del español, edd. Rafael Cano Aguilar/María Teresa Echenique Elizondo, Madrid, Gredos, 2000, vol. 1, 210 234.

Martínez, José Antonio, Propuesta de gramática funcional, Madrid, Istmo, 1994.

McNally, Louise/Boleda, Gemma (2004), Relational Adjectives as Properties of Kinds, in: Olivier Bonami/Patricia Cabredo Hofherr (edd.), Empirical Issues in Formal Syntax and Semantics 5, Paris, CSSP, 2004, 179-196.

Morreale, Margherita, El superlativo en -issimo y la versión castellana del Cortesano, RFE 39 (1955), 46-60.

Navas Ruiz, Ricardo, En torno a la clasificación del adjetivo, in: Strenae. Estudios de Filología e Historia dedicados al Prof. Manuel García Blanco, Salamanca, Universidad, 1962, 369-374.

Pustejovsky, James, The Generative Lexicon, Cambridge, MIT Press, 1995.

RAE, Esbozo de una nueva gramática de la lengua española, Madrid, Espasa Calpe 1973 (en especial, 195-200 y 416-420). 
Rainer, Franz, La derivación adjetival, in: Bosque/Demonte 1999, 445-482.

Santos Río, Luis, Sobre el concepto de adjetivo argumental, con especial referencia al español, in: Wotjak 2000, 275-291.

Schmidt, Reinhard, L'adjectif de relation en français, italien, anglais et allemand. Étude comparée, Göppingen, Kümmerle, 1972.

Serradilla Castaño, Ana, Las completivas en cronistas hispanos, indios y mestizos: estudio comparativo, in: Azucena Palacios/Ana Isabel García (edd.), El indigenismo americano III. Actas de las Terceras Jornadas sobre Indigenismo Americano, Universidad Autónoma de Madrid, 6, 7, 8 y 9 de marzo de 2001, Valencia, Universitat de Valencia, 2002, 177-197.

Serradilla Castaño, Ana, El caso de «carnal»: un ejemplo relativamente temprano del paso de adjetivo relacional a adjetivo valorativo, in: Javier Elvira et al. (edd.), Reinos, lenguas y dialectos en la Edad Media ibérica. La construcción de la identidad (Homenaje a Juan Ramón Lodares), Frankfurt am Main/Madrid, Vervuert/ Iberoamericana (en prensa).

Spitzová, Eva, Rasgos morfológicos de los adjetivos relacionales españoles: sistema y norma, Fremdsprachen 31 (1987), 33-36.

Wotjak, Gerd (ed.), En torno al sustantivo y adjetivo en español actual. Aspectos cognitivos, semánticos, (morfo)sintánticos y lexicogenéticos, Frankfurt am Main/ Madrid, Vervuert/Iberoamericana, 2000.

\section{Madrid}

Ana Serradilla Castaño 